\title{
Social externalities, endogenous childcare costs, and fertility choice
}

\author{
Ratbek Dzhumashev ${ }^{1}$ (D) . Ainura Tursunalieva ${ }^{2}$
}

Received: 2 February 2021 / Accepted: 17 December 2021 / Published online: 28 January 2022

(C) The Author(s) 2022

\begin{abstract}
We reconcile the steep decline in fertility rates during the demographic transition with the fertility rebound observed in recent decades in high-income countries. The micro-foundations of the optimal choice of agents in our expanded model include endogenous childcare costs and social externalities stemming from human capital, consumption, and fertility norms. Combining these factors with the quality-quantity trade-off in fertility choice explains the inverse J-shaped relationship between fertility and economic development. Moreover, the simulated average fertility rates based on the model are reasonably consistent with the observed pattern of the evolution of the cohort fertility rates in high-income countries. Sensitivity analyses show that the model fits historical cohort fertility rates only when it includes the effects of social externalities and endogenous childcare costs.
\end{abstract}

Keywords Fertility rate $\cdot$ Social externalities $\cdot$ Childcare costs .

Demographic transition $\cdot$ Fertility rebound

JEL Classification J11 $\cdot$ J13

\section{Introduction}

In this paper, we aim to enhance the explanation for the fertility dynamics observed in high-income countries. Our motivation stems from the fact that there is no clear

\footnotetext{
Responsible editor: Gregory Ponthiere

Ratbek Dzhumashev

ratbek.dzhumashev@monash.edu

Ainura Tursunalieva

ainura.tursunalieva@monash.edu

1 Department of Economics, Monash University, Wellington Rd, Clayton, 3800, Victoria, Australia

2 Department of Banking and Finance, Monash University, 900 Dandenong Rd, Caulfield East, 3145, Victoria, Australia
} 


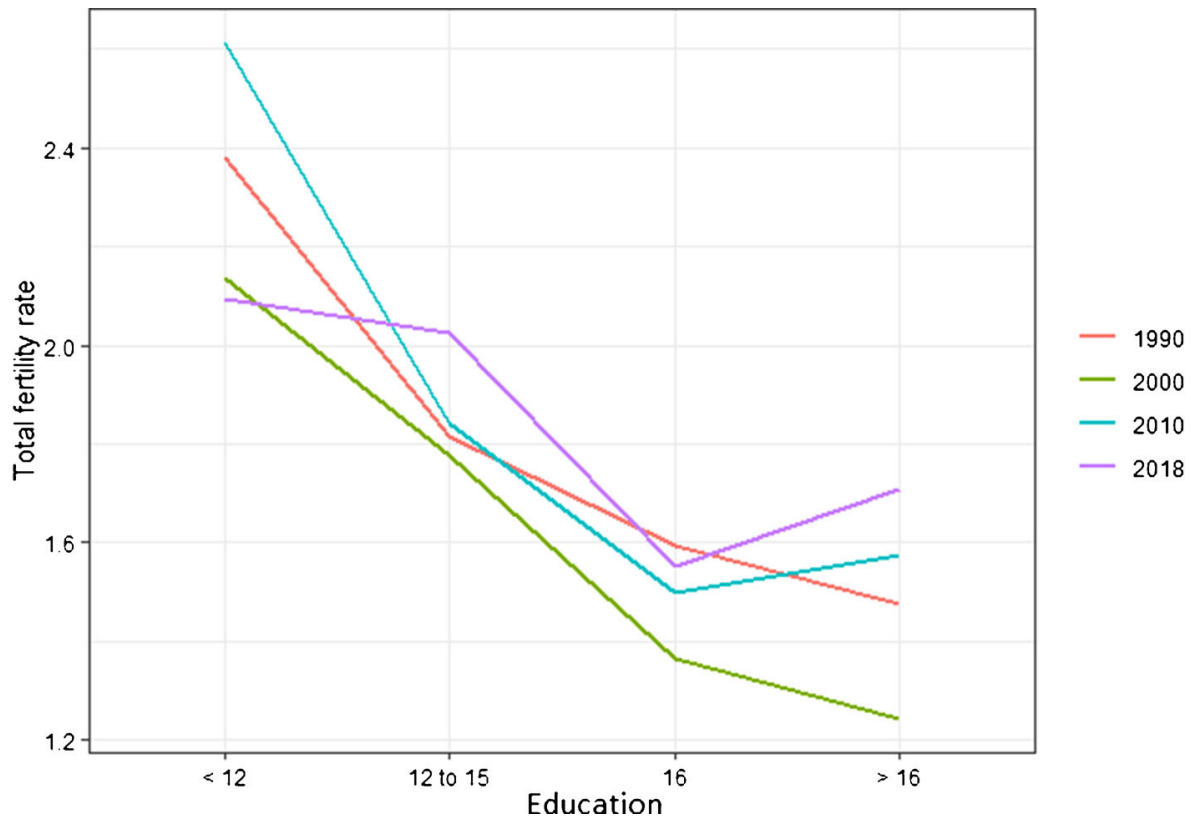

Fig. 1 Evolution of the fertility differentiation across education levels in the USA. Data from the General Social Survey (GSS) by Norc at the University of Chicago, https://gssdataexplorer.norc.org/

explanation within the same theoretical framework for the fertility decline during the demographic transition and the reversal of the fertility decline above a certain income threshold.

Although the demographic transition and the factors causing the fertility decline have been examined extensively, the fertility rebound is a relatively new phenomenon that has not been adequately analyzed and understood by researchers. ${ }^{1}$ To this end, several recent studies corroborate that the decline in average fertility rates has reversed in high-income countries in recent decades. ${ }^{2}$

A fertility rebound also occurs as a relative increase in fertility rates of highincome agents in the cross-section of the population (Hazan and Zoabi 2015). Such a cross-sectional rebound in fertility is represented by an inverse J-shaped curve. For example, Fig. 1 shows a curve of the nexus between the total fertility rate (TFR) and years of education based on US data. The figure shows that the relationship between

\footnotetext{
${ }^{1}$ The fertility decline during the demographic transition has been attributed to the quantity-quality tradeoff (Becker and Lewis 1973; Becker and Tomes 1976; Willis 1973; Barro and Becker 1989). Maruyama and Yamamoto (2010) find that the expansion in the variety of consumption goods reduces the relative price of a composite of differentiated goods compared to child-rearing costs and thus decreases fertility rates. Foreman-Peck and Zhou (2021) argue that lower mortality induces more investment in children and young people. Due to real wage growth, this change, eventually, leads to fertility decline.

${ }^{2}$ See, e.g., Bongaarts and Sobotka (2012), Day (2016), Dominiak et al. (2015), Futagami and Konishi (2019), Goldstein et al. (2009), Hirazawa and Yakita (2017), Lacalle-Calderon et al. (2017), Luci and Thévenon (2011), Mavropoulos and Panagiotidis (2021), Myrskylä et al. (2009), and Nakagaki (2019), and Ohinata and Varvarigos (2019).
} 

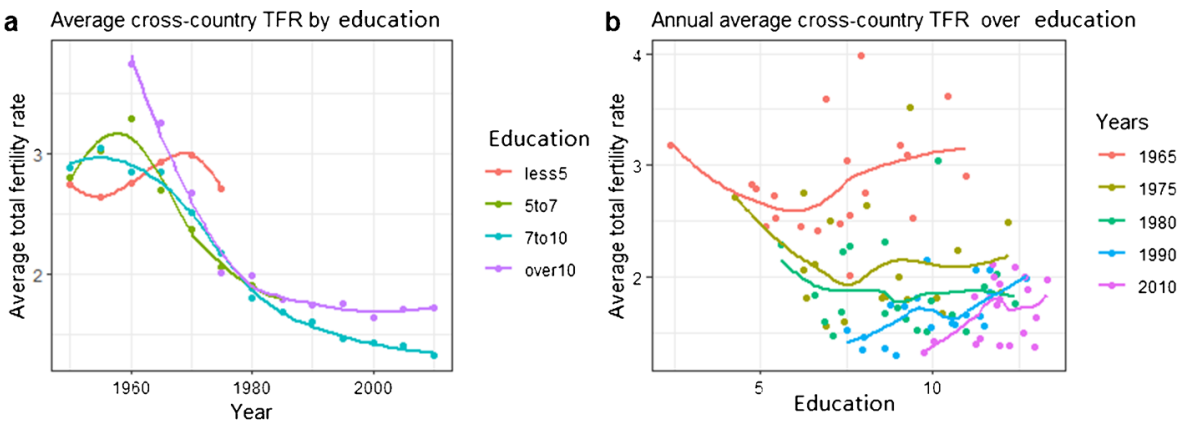

C Average TFR over time
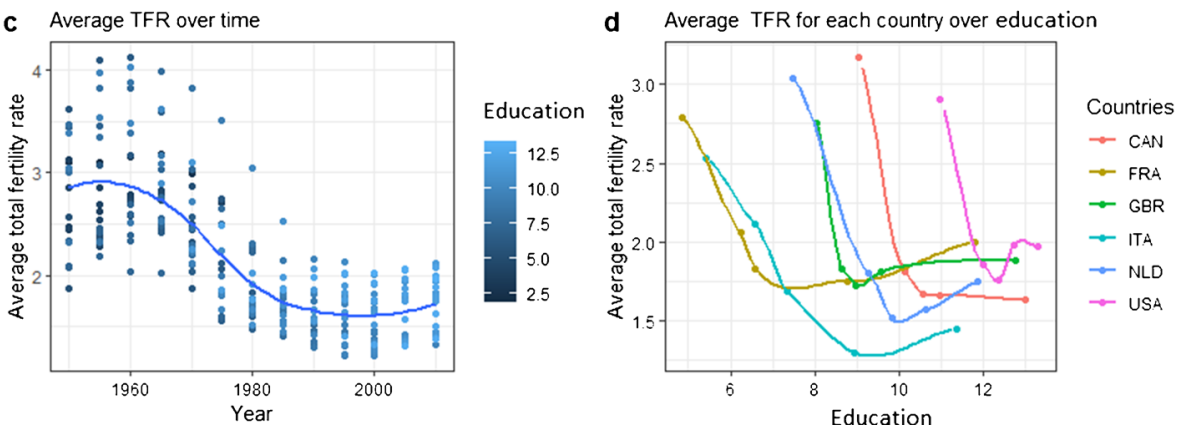

Fig. 2 Total fertility rates-education nexus in a sample of high-income countries, 1960-2010. Except in (d), the following countries are included: Austria, Australia, Belgium, Denmark, Finland, France, Germany, Greece, Iceland, Ireland, Italy, the Netherlands, Norway, Portugal, Spain, Sweden, the UK, and the USA. The average years of education and fertility rates by country are used, except in (a). In (a), the average fertility rates are calculated for a group of countries with the same average education level in a given year. The curves are determined using the loess smoothing method. Source of data: World Development Indicators, World Bank, which includes the Barro and Lee dataset on education

fertility rates and years of education changed over time. In 1990 and 2000, the fertility rates declined with higher levels of education. However, in 2010 and 2018, fertility rates rebounded for high-income women. Another notable pattern is that the fertility rates in 2010 and 2018 are higher compared with those in 2000 at all education levels, thereby implying that the average fertility rates have risen in recent years. In addition, the fertility rates of high-income women with the same education levels in 2018 were higher than in 2010. Thus, based on the observations above, we can conclude that fertility rates rebound in the cross-section of the population and the shifts in the relationship between fertility and human capital levels increased the average fertility rates over time.

The rebound of the average fertility rates is illustrated in the following examples. Figure 2 shows that an inverse J-shaped relationship between the average TFR and the average human capital level is present for high-income countries in recent years. Similar patterns can be detected in the evolution of the country average cohort fertility rates (CFRs). Figure 3 shows the country average CFRs have a similar inverse Jshaped pattern over time (Fig. 3, panel $d$ ). The evolution of the nexus between CFRs and education levels is not homogeneous across education levels and countries. The 

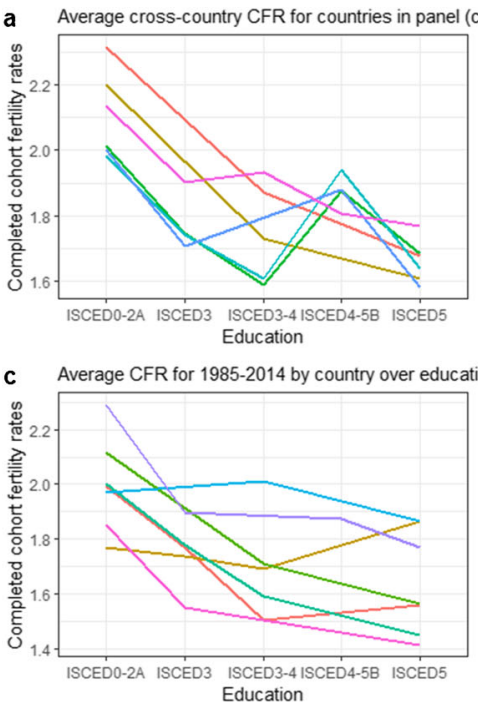
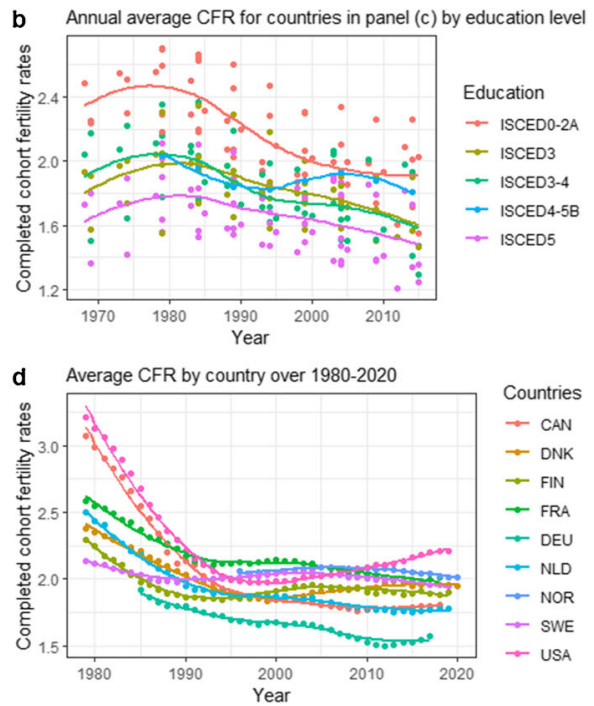

Fig. 3 Cohort fertility-education nexus in a sample of high-income countries. In (b) and (d), the following countries are included: Canada, Denmark, Finland, France, Germany, the Netherlands, Norway, Sweden, and the USA. In (a) and (c), the following countries are included: Austria, Belgium, Finland, France, Germany, Spain, and Italy. The curves in (b) and (d) are determined using the loess smoothing method. Educational level is coded according to the International Standard Classification of Education 1997 (ISCED). ISCED0-2A stands for "no to lower-secondary education"; ISCED3-4 — "upper-secondary education to post-secondary non-tertiary education"; ISCED4-5B — "up to first stage of tertiary education"; ISCED5 - "tertiary education." It is assumed that cohort fertility is completed when a woman is 44 years old. Source of data: (a), (b), and (c) Zeman et al. (2017); (d) Human Fertility Database (2021)

cohort fertility rates of women with basic tertiary education (ISCED4-5B) increased after 1999 (Fig. 3, panels $a$ and $b$ ). In 2014, the CFRs of women with post-secondary education (ISCED3-4) and tertiary education (ISCED5) were considerably higher compared with the CFRs in previous years.

The reason for the inverse J-shaped pattern between economic development and fertility remains ambiguous from the theoretical perspective. First, the literature highlights that the steepness of the decline in fertility rates during the demographic transition and the shifts in the income-fertility relationship over time cannot be fully explained only by the trade-off between the quantity and quality of children caused by income growth and the related decline in infant and child mortality (Doepke 2005; Jones et al. 2010). This implies that the theoretical framework focusing on fertility choice lacks important factors that contribute to the observed fertility decline. Second, the literature does not provide a clear explanation for the factors causing a rebound in the average fertility rates. ${ }^{3}$

\footnotetext{
${ }^{3}$ Several empirical studies find that such a fertility rebound is driven by labor productivity and female emancipation measured by the gender gap or labor participation (Mavropoulos and Panagiotidis 2021; Nakagaki 2019). Lacalle-Calderon et al. (2017) also find that the higher the fertility rate at the start of the demographic transition, the higher the gross domestic product per capita needed to reverse fertility decline.
} 
Although Day (2016), Futagami and Konishi (2019), and Hirazawa and Yakita (2017), and Ohinata and Varvarigos (2019) achieved significant progress in analyzing the forces behind the recent fertility rebound, clear insights into some important aspects of this phenomenon are still missing. These studies on the fertility rebound identified that the decreasing relative costs of child-rearing (childcare and education costs) and longevity are preventing further decline or driving the fertility rates upward. However, these studies are based on models that lack some important features: Social externalities or human capital accumulation are not considered (Day 2016; Futagami and Konishi 2019); the fertility rebound cannot be explained if the opportunity cost of child-rearing is used instead of the direct cost (Ohinata and Varvarigos 2019); and the fertility rebound cannot be explained if the old generation is not allowed to work (Hirazawa and Yakita 2017). Finally, the literature does not provide a comprehensive explanation for the relationship between the fertility rebound observed in the cross-section of agents (Hazan and Zoabi 2015) and the dynamic rebound in the average fertility rates.

To address the issues above, we extend the standard fertility choice model ${ }^{4}$ by incorporating additional features. First, our model incorporates the following factors along with agents' human capital: consumption and human capital externalities, the probability of child survival, social norms related to the number of children, relative childcare costs, and substitution of mothers' child-rearing time with fathers' time. Second, we capture the nexus between income and fertility in a more general form by modeling child-rearing costs using the opportunity cost of labor and the economic cost of education. Third, our approach generalizes the modeling of childcare time costs by incorporating market-based childcare services (Hazan and Zoabi 2015) and fathers' involvement in child-rearing (Siegel 2017). Finally, we consider the effect of externalities on an agent's consumption stemming from others' consumption in society, which also affects fertility choice through the budget constraint.

The analysis based on the extended fertility choice model yields the following results. The steep decline in fertility rates during the demographic transition is caused by the quality-quantity trade-off, which is augmented by the fertility effects of social externalities and increases in child survival rates. Specifically, consumption externalities reduce the fertility rate by increasing the marginal value of consumption compared with that of having children. Moreover, the higher benchmark human capital negatively affects fertility by raising the survival and education of children and benchmark consumption. In addition, the declining benchmark fertility rate has a magnifying effect on the overall fertility choice dynamics. Therefore, the observed steepness of the decline in fertility during the demographic transition is also attributed to the changes in the benchmark fertility that reinforce the fall in fertility rates.

The paper also suggests an explanation for the recent rebound in fertility rates in high-income countries. This rebound is caused by the interplay of several factors. First, at significantly high benchmark levels of human capital and consumption, the marginal effect of these external factors on fertility diminishes. Therefore, further increases in benchmark levels of human capital and consumption do not have any

\footnotetext{
4 e.g., Barro and Becker (1989) and de la Croix and Doepke (2004), and Doepke (2005).
} 
additional negative effect on the fertility rate. Second, a decrease in child-rearing costs generated by market-based childcare services causes a fertility rebound among high-income agents. Given the increase in the benchmark fertility rates, externalities stemming from fertility norms push the average fertility rates up. ${ }^{5}$ This positive effect of fertility externalities becomes relatively strong due to the presence of diminishing marginal effects of consumption and human capital externalities on fertility with income levels. As a combined outcome of these two effects, the average fertility rates increase.

This paper contributes to the literature by developing a novel explanation for the fertility rebound in a more general setting than the ones considered in existing studies. For example, Hazan and Zoabi (2015) examine a cross-sectional fertility rebound; however, unlike our model, their model is not dynamic. In addition, we capture the discontinuous effect of heterogeneity among agents on childcare costs by making the childcare cost endogenous only for agents who have sufficiently high human capital and thus can afford market-based childcare services. Our paper also differs from papers that address the fertility rebound from a dynamic perspective. Unlike Futagami and Konishi (2019), Hirazawa and Yakita (2017), and Ohinata and Varvarigos (2019), by accounting for the heterogeneity of agents, our model captures social externalities stemming from differences among agents in consumption, human capital, and fertility. In our model, the rebound in the average fertility rates does not require a decrease in inequality, as in Day (2016). In contrast, we use inequality (heterogeneity) to generate social externalities in terms of consumption, human capital, and fertility norms. From this perspective, our model reconciles the rebound in the fertility of high-income agents relative to low-income agents and its dynamic implications for the average fertility rebound.

We test the findings of this study by simulating fertility rates using plausible parameter values calibrated to match the empirical moments from the distributions of human capital and completed cohort fertility rates for high-income countries. We use average completed cohort fertility rates as the appropriate statistic to represent the average fertility rate captured in our model, because the model determines the completed fertility rates of the adult agents in each generation. ${ }^{6}$

The simulated average fertility rates exhibit an inverse J-shaped relationship between human capital and completed cohort fertility observed in high-income economies (Figs. 4 and 5). Specifically, the simulated fertility rates fall initially, emulating the demographic transition; then, at higher income levels, the fertility rates rebound and reach the level of average cohort rates observed in high-income economies over 1980-2020. The simulated model also generates an inverse J-shaped

\footnotetext{
${ }^{5}$ The increase in the fertility rate does not seem to be driven by the immigrant population's fertility rates, which may be higher than that of the local population. For example, Lanzieri (2013) indicates that in most high-income European countries, the immigrant population exhibits lower fertility rates than the local population.

${ }^{6}$ Importantly, the dynamics of the cohort fertility rates reflect the demographic changes quite well. For example, by investigating the cohort fertility evolution, Albanesi and Olivetti (2014) Bailey and Hershbein (2018), and Chabé-Ferret and Gobbi (2018) show that the baby boom can be attributed to a decline in maternal mortality and uncertainty.
} 


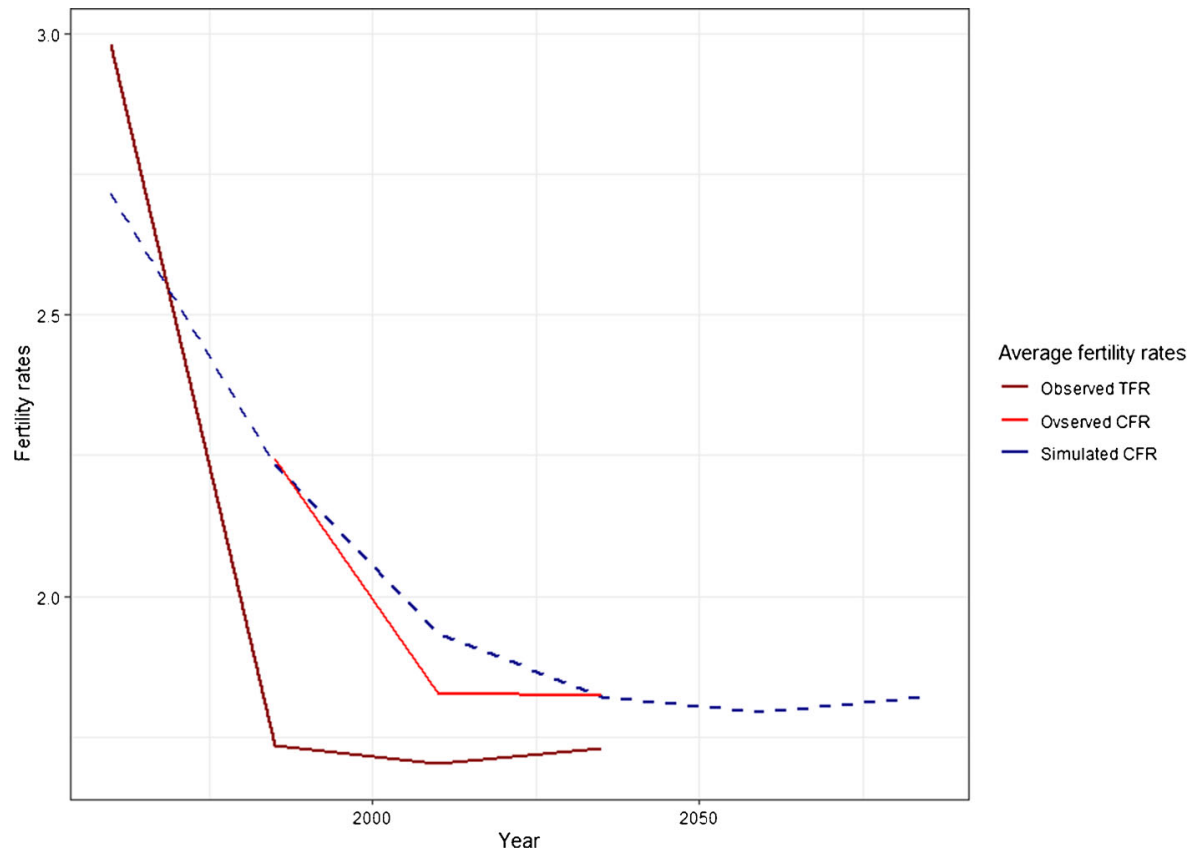

Fig. 4 Simulated and observed fertility rates in high-income countries, 1960-2085. Source of data: The TFRs are from United Nations, Department of Economic and Social Affairs, Population Division. The CFRs are from Human Fertility Database (2021). See Appendix A.6. The model is calibrated to target the CFR for 1985 . The simulated total fertility rates (SCFRs) to 2105 are presented. The horizontal axis measures time in years, and the vertical axis measures the fertility rates. Each generation spans 25 years

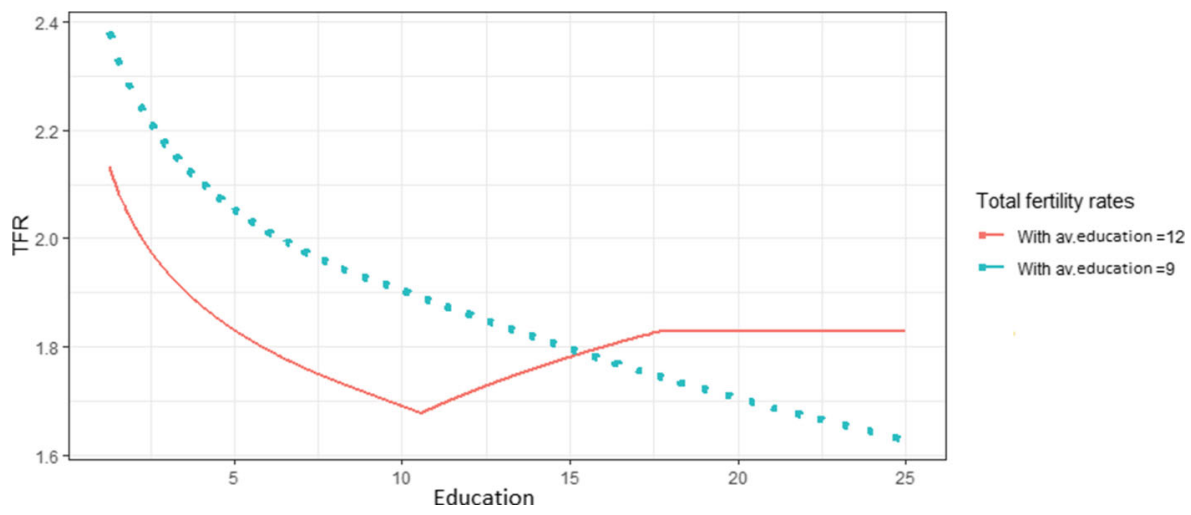

Fig. 5 Simulated cross-section fertility-human capital relationship for distributions with different initial average human capital (education) $\bar{h}_{1}$. The parameter values are given in Appendix A.7 
fertility-income relationship in the cross-section of heterogeneous agents with high average years of education (see below).

Therefore, our model captures the relationship between human capital inequality and fertility in the cross-section, which, in the presence of social externalities and endogenous childcare costs and child survival, provides a plausible explanation for the non-monotone evolution dynamics of fertility over long time horizons. In addition, we experiment with the calibrated model by shutting down effects stemming from social externalities. The results show that one cannot fully emulate the observed pattern of fertility evolution in high-income countries by omitting the social externalities and endogenous childcare costs from the model.

The rest of the paper is organized as follows. In Section 2, we describe the basic model with social externalities. In Section 3, we present an equilibrium analysis. In Section 4 , we carry out a calibration analysis to establish whether the theoretical model can capture the documented evolution of the average fertility rates by exhibiting their initial decline during the demographic transition and the subsequent rebound at high-income levels. In Section 5, we conclude the paper.

\section{Model}

\subsection{Household preferences}

In our overlapping-generation model (OLG), we assume that agents live in two periods: childhood and adulthood. Adult agents are indexed by $i$ and are endowed with one unit of time, which they supply inelastically in a competitive labor market and child-rearing. We also assume that the agents are heterogeneous in terms of their human capital levels. The probability distribution function (pdf) of human capital over the adult population is given by $f\left(h_{i t}\right)$. Adult agents care about their consumption, $c_{i t} \geq 0$, the number of children surviving to adulthood with the probability, $\pi_{i t}$, and their human capital, $h_{i t+1}$. This assumption implies that the number of children born and alive after infancy is given by $\pi n_{i t}$.

The probability of survival is defined similarly to Blackburn and Cipriani (2002) and is given as a function of the level of the parents' human capital and other external factors:

$$
\pi\left(h_{i t}, \bar{h}_{t}\right)=\min \left(1, \underline{\pi} \bar{h}_{t}^{1-\sigma} h_{i t}^{\sigma}\right),
$$

where $0<\underline{\pi}<1, \sigma<1$; thus, if $\pi<1$,

$$
\frac{\partial \pi_{i t}}{\partial h_{i t}}=\sigma \underline{\pi}\left(\frac{\bar{h}_{t}}{h_{i t}}\right)^{1-\sigma}>0,
$$

and

$$
\frac{\partial^{2} \pi_{i t}}{\partial h_{i t}^{2}}=-(1-\sigma) \sigma \underline{\pi} \bar{h}_{t}^{1-\sigma} h_{i t}^{\sigma-2}<0 .
$$

In our specification, we follow Strulik (2004) and assume that $\pi$ is partly determined by parents' decisions and partly by external factors. It is reasonable to assume that the latter part of survival probability depends on overall healthcare conditions 
that are driven by the average (benchmark) human capital level, $\bar{h}_{t}$. However, this formulation of the probability of survival implies that for high human capital levels, it is possible that $\pi_{i t}=1$. That is, a further increase in human capital does not affect survival of a child, as soon as $\pi=1$.

In our model, fertility optimization is affected by externalities stemming from the average consumption, fertility, and human capital levels. Specifically, the agent obtains utility not only from their consumption and the effective number of children but also from the relative level of their consumption and fertility. Thus, the effective input of the consumption part in the utility function is determined as $c_{i t}^{1-\delta}\left(\frac{c_{i t}}{\bar{c}_{t}}\right)^{\delta}$, where $\bar{c}_{t}$ is the level of the benchmark (average) consumption. As the individual consumption level depends on the individual human capital level, it is reasonable to expect that the benchmark (average) consumption level, $\bar{c}_{t}$, depends positively on the benchmark (average) human capital, $\bar{h}_{t}$. Thus, this relationship can be expressed as $\bar{c}_{t}=p \bar{h}_{t}$, where $p<1$ is the marginal propensity to consume. Analogously, the effective input of the fertility part in the utility function is given as $n_{i t}^{1-\varepsilon}\left(\frac{n_{i t}}{\bar{n}_{t}}\right)^{\varepsilon}$, where $\bar{n}_{t}$ is the level of the benchmark (average or another reference level) fertility. In other words, the level of utility depends on agent's consumption and fertility levels. In addition, the level of unity depends on the externalities stemming from the standing of the agents relative to the social benchmark. ${ }^{7}$ We impose the restrictions $\delta<1$ and $\varepsilon<1$ to ensure that the instantaneous utility is an increasing function of the absolute level of the household's consumption and fertility.

Following de la Croix and Doepke (2003) and Fioroni (2010), and Omori (2009), the human capital level of a child $h_{i t+1}$ evolves according to

$$
h_{i t+1}=B_{t}\left(\bar{h}_{t}^{\beta_{2}} h_{i t}^{\beta_{1}}\right)^{1-\theta} e_{i t}^{\theta},
$$

where $e_{i t}$ is parents' education spending, $h_{i t}$ is the level of the parents' human capital, and $\bar{h}_{t}$ is the benchmark human capital level, which captures the positive effect of externalities on human capital accumulation. To rule out the implausible case of human capital accumulation of an individual decreasing in human capital externalities and in parents' human capital, we assume $0<\theta<1,0<\beta_{1}<1$ and $\beta_{1}+\beta_{2} \leq 1$. These restrictions allow the education function to be in line with the empirical evidence. ${ }^{8}$ The last restriction is used to accommodate the possibility of decreasing returns to scale in terms of the contribution of human capital (parental and external) to the human capital accumulation of the next generation. The productivity coefficient of the education function is given by $B_{t}>0$. This coefficient is useful for scaling the results in a numerical simulation of the model. We assume that this coefficient increases along with the average human capital and is expressed as

\footnotetext{
${ }^{7}$ In related literature, it is assumed that consumption and fertility externalities depend on the respective averages for the society (e.g., Bhattacharya and Chakraborty 2012; Munshi and Myaux 2006; Palivos 2001). However, in general, the benchmark levels for consumption and fertility can be different from the respective averages and may be driven by the behavioral patterns of the agents with higher social status.

${ }^{8}$ Unlike de la Croix and Doepke (2003) and Fioroni (2010), and Omori (2009), the focus of the present study is not on determining the impact of education spending on fertility; thus, for simplicity, we assume that human capital accumulation is possible only with non-zero spending on education.
} 
$B_{t}=B_{0} \bar{h}_{t}^{\xi}$, where $B_{0}$ is the initial value of the coefficient, and $\xi$ is the parameter capturing the effect of average human capital $\bar{h}_{t}$ on the overall productivity of the education system.

In light of the discussion above, the utility function of an agent incorporates social externalities along with the standard choice variables, such as consumption, education spending, and the number of children. ${ }^{9}$ We state the utility function of an agent in the following constant elasticity of substitution (CES) form:

$$
U_{i t}=\gamma\left[\alpha\left(\bar{c}_{t}^{-\delta} c_{i t}\right)^{\rho}+(1-\alpha)\left(\bar{n}_{t}^{-\varepsilon} n_{i t} B_{t}\left(\bar{h}_{t}^{\beta_{2}} h_{i t}^{\beta_{1}}\right)^{1-\theta} \pi e_{i t}^{\theta}\right)^{\rho}\right]^{\frac{1}{\rho}} .
$$

Note that the expressions above for consumption and fertility inputs in the utility function are simplified to $c_{i t} \bar{c}_{t}^{-\delta}$ and $n_{i t} \bar{n}_{t}^{-\varepsilon}$ as they are given in (3).

\subsection{Household budget constraint}

Agents generate income by working for firms. We assume a simple production function specified as follows:

$$
y_{i t}=w h_{i t} l_{i t}
$$

where $w$ is the wage rate, and $l_{i t}$ is the amount of labor supplied (time spent working). Normalizing the time available to unity, we impose the following restriction on the labor supply:

$$
0<l_{i t} \leq 1
$$

Given that income is a linear function of effective labor, for simplicity, we normalize the wage rate, $w$, to 1 . This form of production modeling is standard for fertility choice models.

Having a child is costly in terms of the time spent on child-rearing. In modeling the child-rearing costs, we adopt a more general approach by allowing for direct costs (Hazan and Zoabi 2006; Ohinata and Varvarigos 2019) and opportunity costs (e.g. de la Croix and Doepke 2003). That is, the cost of child-rearing includes the time cost and the monetary cost of education. As the length of childhood is determined by nature, we can assume that rearing each child requires time that is equal to $\tau$.

Following Day (2016) and Hazan and Zoabi (2015), we assume that parents look after their children some of the time and can hire childcare services for the rest of the time. We build this rationale from the fact that without childcare services, the cost of childcare is captured by the time parents spend looking after their children. By definition, this means that the total time spent raising a child is fixed and comprises time parents spent raising their children and time children spent at hired childcare. We assume that the average human capital level of childcare service workers is given by $\underline{h}_{t} \in\left(0, \bar{h}_{t}\right)$. To abstract from the problem of modeling the childcare labor market,

\footnotetext{
${ }^{9}$ We follow de la Croix and Doepke (2003) and Fioroni (2010) in terms of conceptual modeling, but we use a different functional form. The reason for this choice is that the CES function is less restrictive than the Cobb-Douglas function employed by these authors, and in the current context, the CES form allows for better tractability. In addition, the externalities or norms can be modeled as the deviation from the average as in Bhattacharya and Chakraborty (2012), for example. However, this form also fits the definitions of spillovers and complementaries, and analytically, it results in the same type of relationship.
} 
we assume this value is determined exogenously as a function of the average human capital. ${ }^{10}$ Therefore, we write the human capital level in the childcare sector as $\underline{h}_{t}=\chi \bar{h}^{v}$, where $0<v<1$, and $\chi>0$.

We integrate childcare services by assuming that the cost of child-rearing for an agent is given by $\psi_{i t} \tau h_{t}$. Here, $\tau$ is the exogenous time cost of raising a child, whereas the childcare cost function is given as follows:

$$
\psi_{i t}=\left\{\begin{array}{l}
1, \text { if } \frac{h_{i t}}{\underline{h}_{t}} \leq 1, \\
\chi \frac{\underline{h}_{t}}{h_{i t}^{v}}, 0<\psi_{i t}<1, \text { if } \frac{h_{i t}}{\underline{h}_{t}}>1 .
\end{array}\right.
$$

That is, only if the level of human capital is greater than the human capital level given in the childcare sector $\left(\underline{h}_{t}\right)$ does a person use childcare services; otherwise, a person uses only their own time. The exact form of the childcare functions is given as

$$
\psi_{i t}=\chi \frac{\underline{h}_{t}}{h_{i t}^{v}} .
$$

The assumed functional form of $\psi_{i t}$ implies that use of childcare services is increasing in the parent's human capital level. Therefore, the higher the parents' education level, the less of their own time parents use for childcare. Thus,

$$
\frac{\partial \psi_{i t}}{\partial h_{i t}}=-\chi \nu \frac{\underline{h}_{t}}{h_{i t}^{(v+1)}}<0 .
$$

In addition, the marginal effect of the parent's human capital is decreasing in the level of her human capital at an increasing rate. Thus,

$$
\frac{\partial^{2} \psi_{i t}}{\partial h_{i t}^{2}}=(1+v) v \chi \frac{\underline{h}_{t}}{h_{i t}^{(v+2)}}>0 .
$$

This assumption is in line with the plausible condition that parents still spend some minimum time raising their children even when they can afford to hire childcare services for the whole time.

This modeling approach also allows us to incorporate the argument by Siegel (2017), who demonstrates that as women's earning capacity rises, housework substitution from husbands to wives decreases the time cost for women; and thus, it decreases the cost of having children. This type of time-cost substitution increases fertility. Therefore, the parameter $v$ captures not only the effect of market-based childcare services but also the substitution of husbands' time spent on childcare. For agents with high enough human capital so that $\psi_{i t}<1$, a further increase in their human capital should decrease the use of their own time in child-rearing; the magnitude of this change also depends on the value of $v$. Another point to note is that to avoid modeling the childcare sector explicitly, and to keep the model simple,

\footnotetext{
${ }^{10}$ It is possible that the level of an individual's human capital is related to the average human capital level. However, this functional relationship may not be simple. Because in our model the main factor is how individual human capital is related to the childcare costs determined by $\underline{h}_{t}$, our specification is capable of mapping the human capital differential to the fertility differential by capturing this link. Because of this rationale, we abstract from modeling the human capital levels in the childcare sector.
} 
we assume that $\psi_{i t}$ captures the effective decrease in the opportunity cost of childrearing net of the cost of childcare services. For example, if an agent decreases the time cost on a child by $30 \%$, but say one-third of that additional time is spent on generating income to cover the cost of childcare services, then the effective value of $\psi_{i t}$ is only 0.8 , not 0.7 . Thus, we assume that parameter $\chi>1$.

Because any decrease in $\psi_{i t}$ implies that the direct time cost of a parent decreases, which increases the fertility rate of the affected agent (as in Day 2016; Hazan and Zoabi 2015; Siegel 2017), taking this structure in childcare, the effective labor supply is expressed as

$$
l_{i t}=\left(1-\psi_{i t} \tau\right) \text {. }
$$

Accounting for the labor supply and the cost of child-rearing, the budget constraint faced by an agent is stated as

$$
c_{i t}=h_{i t}\left[1-\left(\tau \psi_{i t}+e_{i t}\right) n_{i t}\right],
$$

where $e_{i t}$ is the amount of income spent on education for each child, and $\tau$ is the time required to raise a child.

\subsection{The role of social externalities in fertility choice}

In the formulation of the utility function given above, we incorporated several social externalities. In this section, we discuss the motivation for adding these externalities and highlight why these externalities are essential in agents' utility maximization.

The critical reason for incorporating consumption externalities into agents' utility function is based on the following intuition: The literature highlighted that consumption externalities have a significant effect on the inter-temporal allocation of individual consumption. Thus, agents jointly consider capital accumulation, fertility, savings, labor supply, and consumption in their choice decision-making process. Therefore, adult agents' marginal utility from consumption depends on social preference levels for consumption measured by the benchmark consumption level, $\bar{c}_{t}$ (Cigno and Rosati 1996; Chen et al. 2015; Park 2018). ${ }^{11}$

The literature on fertility choice (Barro and Becker 1989; de la Croix and Doepke 2004; Doepke 2005) assumes that agents care about the quality and number of their children, expressed as the following product: $n_{i t} h_{i, t+1}$. Both variables are subject to external effects. For example, Bhattacharya and Chakraborty (2012), Dasgupta (2000), Goto (2008), and Munshi and Myaux (2006), and Palivos (2001) link the fertility evolution to social norms related to the number of children families choose to have. The finding that the fertility rebound income level depends on the fertility rate at the start of the demographic transition (Lacalle-Calderon et al. 2017) also highlights the existence of fertility externalities. Based on a rationale similar to the

\footnotetext{
${ }^{11}$ The implications of social externalities for a range of economic problems have been investigated. These externalities affect asset pricing (Abel 1990, 1999; Constantinides 1990; Campbell and Cochrane 1999; Gali 1994), the consumption decision (Dupor and Liu 2003), and capital accumulation and growth (Cooper et al. 2001; Fisher and Hof 2000; Liu and Turnovsky 2005; Pool et al. 2015). Agarwal et al. (2020), Clark and Oswald (1996), Easterlin (1995), and Kuhn et al. (2011), and Oswald (1997) find empirical evidence supporting the existence of consumption externalities.
} 
case of consumption externalities, we assume that the average number of children per parent, $\bar{n}$, exerts an additional effect on the utility of an agent gained from having a certain number of children. ${ }^{12}$

Several studies demonstrate that average human capital and income levels in society (Hazan and Zoabi 2006; Kalemli-Ozcan 2002; Strulik 2004) generate externalities that improve a child's health and consequently, increase the relative return to the quality of a child. By driving economic conditions, these externalities affect investment levels in children's education and thus impact the quality-quantity tradeoff in fertility choice. Moreover, the average human capital level in a society provides an external effect on fertility rates through the impact on education costs (de la Croix and Doepke 2003). Formally, de la Croix and Doepke (2003) argue that the evolution process of human capital depends not only on educational spending, $e_{i t}$, and the level of parents' human capital, $h_{i t}$, but also on the (average) benchmark human capital level, $\bar{h}_{t}$, which exerts positive externalities on human capital accumulation.

In Section 3, we demonstrate how the interplay of these social externalities and changes in child-rearing costs drives an inverse J-shaped relationship between fertility and economic development. Moreover, a sensitivity analysis of the calibrated model in which these externalities mechanisms are shut down that only by accounting for these externalities can we emulate the observed average fertility dynamics in high-income countries.

\subsection{Aggregate variables}

Given that we are dealing with heterogeneous agents, we consider how some of the variables are aggregated. The average human capital level, $\bar{h}_{t}$, is given as

$$
\bar{h}_{t}=\int_{h_{\min }}^{h_{\max }} h_{i t} f\left(h_{i t}\right) d h_{i t} .
$$

The total population evolves as the product of the weighted average fertility rate and the population in the current period:

$$
P_{t+1}=P_{t} \int_{h_{\min }}^{h_{\max }} n_{i t} \pi_{i t} f_{t}\left(h_{i t}\right) d h_{i t} .
$$

The average fertility rate is determined by

$$
\bar{n}_{t}=\int_{h_{\min }}^{h_{\max }} n_{i t} f_{t}\left(h_{i t}\right) d h_{i t},
$$

whereas the average consumption level is determined by

$$
\bar{c}_{t}=\int_{h_{\min }}^{h_{\max }} c_{i t} f_{t}\left(h_{i t}\right) d h_{i t} .
$$

\footnotetext{
12 We follow Goto (2008) and Palivos (2001), who employ the average fertility rate as the measure of the social norm in fertility preferences.
} 
The distribution of human capital evolves as follows ${ }^{13}$ :

$$
f_{t}\left(h_{i t}\right)=\left[\frac{P_{0}}{P_{t}} \prod_{\tau=0}^{t} n_{i \tau}\right] f_{0}\left(h_{i 0}\right) .
$$

\subsection{The agent's problem}

In the setting specified above, the agent's problem is given by:

$$
\begin{gathered}
\max _{c, n, e} U=\gamma\left[\alpha\left(\bar{c}_{t}^{-\delta} c_{i t}\right)^{\rho}+(1-\alpha)\left(B_{t} \bar{n}_{t}^{-\varepsilon}\left(\bar{h}_{t}^{\beta_{2}} h_{i t}^{\beta_{1}}\right)^{1-\theta} e_{i t}^{\theta} \pi_{t} n_{i t}\right)^{\rho}\right]^{\frac{1}{\rho}}, \\
\text { s.t. } c_{i t}=h_{i t}\left[1-\left(\psi_{i t} \tau+e_{i t}\right) n_{i t}\right] .
\end{gathered}
$$

In the problem statement, we dropped the non-negativity constraints imposed on $c_{i t}$ and $h_{i t}$, because they are non-binding for this class of problems.

The agent's problem can be solved by maximizing the following Lagrangian:

$$
\begin{array}{r}
L=\gamma\left[\alpha\left(\bar{c}_{t}^{-\delta} c_{i t}\right)^{\rho}+(1-\alpha)\left(B_{t} \bar{n}_{t}^{-\varepsilon}\left(\bar{h}_{t}^{\beta_{2}} h_{i t}^{\beta_{1}}\right)^{1-\theta} e_{i t}^{\theta}\left(\pi_{i t} n_{i t}\right)\right)^{\rho}\right]^{\frac{1}{\rho}} \\
+\lambda\left[h_{i t}\left[1-\left(\psi_{i t} \tau+e_{i t}\right) n_{i t}\right]-c_{i t}\right] .
\end{array}
$$

Solving for the optimal values of $e_{i t}$ and $n_{i t}$, we obtain (see Appendix A.1 for details):

$$
\begin{gathered}
e_{i t}^{*}=\frac{\theta h_{i t} \tau \psi_{i t}}{1-\theta}, \\
n_{i t}^{*}=\frac{h_{i t}\left(\frac{h_{i t} \tau \psi_{i t}}{1-\theta} \alpha\right)^{\frac{1}{\rho-1}}}{\left[(1-\alpha)\left(B_{t} \bar{n}_{t}^{-\varepsilon}\left(\bar{h}_{t}^{\beta_{2}} h_{i t}^{\beta_{1}}\right)^{1-\theta} \pi_{i t}\left(\frac{\theta h_{i t} \tau \psi_{i t}}{1-\theta}\right)^{\theta}\right)^{\rho}\right]^{\frac{1}{\rho-1}} \bar{c}_{t}^{\frac{\delta \rho}{\rho-1}}+\left[\left(\frac{h_{i t} \tau \psi_{i t}}{1-\theta}\right)^{\rho} \alpha\right]^{\frac{1}{\rho-1}}}
\end{gathered}
$$

The equilibrium consumption level is determined using the budget constraint (14).

\subsection{Definition of equilibrium}

Given an initial distribution of human capital $f_{0}\left(h_{0}\right)$, an initial population size $P_{0}$, and the human capital level in the childcare sector $\underline{h}_{t}$, an equilibrium consists of sequences of aggregate quantities $\left\{\bar{c}_{t}, \bar{h}_{t}, \bar{n}_{t}, P_{t+1}\right\}$, distributions $f_{t}\left(h_{i t}\right)$,

\footnotetext{
${ }^{13}$ To obtain this formula, consider a change in the human capital distribution from period 0 to period 1 . In period 0 , the number of agents with human capital $h_{i 0}$ is found as the product of the share of this type of agent and the total population, $f_{0}\left(h_{i 0}\right) P_{0}$. In period 1, each agent of type $i$ will have $n_{i 1}$ children with $h_{i 1}$ human capital. Given that the total adult population in period 1 is $P_{1}$, the share of these type $i$ agents is found to be $f_{1}\left(h_{i 1}\right)=\frac{\left[f_{0}\left(h_{i 0}\right) P_{0}\right] n_{i 1}}{P_{1}}$. Using this recursive rule, one obtains the general rule given with (12).
} 
and decision rules for consumption, fertility, education spending, and human capital accumulation $\left\{c_{i t}, n_{i t}, e_{i t}, h_{i t+1},\right\}$ such that:

- the individual's decision rules $\left\{c_{i t}, n_{i t}, e_{i t}, h_{i t+1}\right\}$ maximize the utility function, subject to constraints (14) and (2) and the evolution of child survival (1) and childcare costs (5);

- markets clear by labor being distributed between childcare of own children and production (6), and in the goods market, the output is allocated among consumption, education spending, and childcare services (7);

- aggregate variables $\bar{h}_{t}, P_{t}, \bar{n}_{t}$, and $\bar{c}_{t}$ are given by (8), (9), (10), and (11), respectively; and

- the distribution of human capital evolves according to (12).

The concavity of the utility function and a linear production function ensures the existence of equilibrium.

\section{Equilibrium analysis}

\subsection{The effect of externalities stemming from others' consumption}

We state the following proposition by analyzing the expression for the equilibrium fertility rate (17).

Proposition 3.1 Consumption externalities exhibit a negative effect on fertility rates. The marginal effect of consumption externalities on fertility diminishes with the increase in the benchmark consumption.

Proof Using (17), it can be verified that $\frac{\partial n_{i t}^{*}}{\partial \bar{c}_{t}}<0$. In addition, it can be shown that $\lim _{\bar{c}_{t} \rightarrow \infty} \frac{\partial n_{i t}^{*}}{\partial \bar{c}_{t}} \rightarrow 0$. Thus, with a rise in benchmark consumption, the marginal effect of consumption externalities on fertility diminishes. See Appendix A.2 for details.

When the benchmark consumption levels increase due to positive externalities, this change lifts the marginal utility of consumption. Given the budget constraint, agents respond to this change by increasing their consumption levels and decreasing their fertility rate. In the earlier stages of the demographic transition, the benchmark consumption levels are relatively low; thus, consumption externalities exert an additional downward push on fertility. This additional pressure on fertility rates stemming from consumption externalities contributes to the observed steep decline in fertility rates. However, there is a limit to this effect stemming from consumption, because the marginal effect of consumption externalities on fertility tends to zero at significantly high levels of benchmark consumption. In other words, after reaching some high threshold values, a further increase in the benchmark consumption levels will not have any further significant effect on agents' fertility. 


\subsection{The effect of externalities stemming from others' human capital}

In this setting, the comparative statics analysis of $n_{i t}$ with regard to $\bar{h}_{t}$ yields the following proposition:

Proposition 3.2 Human capital externalities exhibit a negative effect on fertility rates. The marginal effect of human capital externalities on fertility diminishes with the increase in the benchmark human capital levels.

Proof Using (17), it can be verified that $\frac{\partial n_{i t}^{*}}{\partial \bar{h}_{t}}<0$. It can also be shown that with an increase in $\bar{h}_{t}$, the marginal effect of human capital externalities on fertility diminishes. That is, we can show that

$$
\lim _{\bar{h}_{t} \rightarrow \infty} \frac{\partial n_{i t}^{*}}{\partial \bar{h}_{t}}=0 .
$$

See Appendix A.3 for details.

This result indicates that when the level of benchmark human capital is above a certain threshold, the fertility rate does not depend on a further increase in the benchmark human capital. In other words, after a certain threshold level is reached, a further increase in levels of benchmark human capital will not have any significant effect on agents' fertility.

\subsection{The effect of externalities stemming from others' fertility}

By analyzing the equilibrium fertility rate given by (17), we can state the following proposition:

Proposition 3.3 In the presence of social externalities stemming from fertility norms (when $\varepsilon>0$ ), an increase in the benchmark level of fertility, $\bar{n}$, raises the fertility rate of an agent.

Proof Using (17), it can be verified that $\frac{\partial n_{i t}^{*}}{\partial \bar{n}_{t}}>0$. See Appendix A.4 for details.

This result indicates that the existence of externalities stemming from the socially desirable level of fertility makes the effect of consumption and human capital externalities even stronger in the early stages of the demographic transition. This outcome occurs because increases in the benchmark levels of consumption and human capital reduce the benchmark fertility rate, which creates additional externalities and exerts additional downward pressure on individual fertility choice. The complementarity of these externalities explains why the fertility rates spiral rapidly downward during the demographic transition. However, when the positive effect of the externalities stemming from fertility norms dominates the effects of other social externalities on 
fertility choice, the condition explains the recent reversal of the fertility decline in high-income countries. We discuss this aspect in more detail in Section 3.5.

\subsection{The role of human capital in the quantity and quality of children}

In this section, we demonstrate that the effect of individual human capital on education spending and fertility rates can be different depending on whether an agent's human capital is above a certain threshold. First, we state the following lemma by analyzing the equilibrium value of education spending given by (16).

Lemma 3.4 Spending on education increases with parents' human capital level. This effect is greater for those who do not use market-based childcare services than for those who use these services.

Proof $e_{i t}^{*}=\frac{\theta h_{i t} \tau \psi_{i t}}{1-\theta}$. Taking the first-order derivative of (16) yields for the case with market-based childcare services:

$$
\frac{\partial e_{i t}}{\partial h_{i t}}=\frac{\psi_{i t} \theta \tau}{(1-\theta)}>0
$$

If the agent does not use market-based childcare services, then we have $\psi_{i t}=1$. Thus, we have

$$
\frac{\partial e_{i t}}{\partial h_{i t}}=\frac{\theta \tau}{(1-\theta)}>0 .
$$

Given that for the case with market-based childcare services $\psi_{i t}<1$, it can be verified that the marginal effect of parents' human capital level on education spending is greater for those who cannot afford market-based childcare services than for those who can.

The positive effect of human capital is in line with the evidence for the relationship between parents' human capital level and spending on children's education (Hazan and Zoabi 2015). Moreover, our result provides a theoretical perspective on the increasing relative cost of private education observed in developed economies. ${ }^{14}$ In particular, we show that agents with lower human capital endowment respond more strongly to the increase in their human capital by investing more in the education of their children.

Next, we analyze the effect of individual human capital on the fertility rate given by (17) and state the following proposition.

\footnotetext{
${ }^{14}$ See the data from the Organisation for Economic Co-operation and Development (OECD, 2021), Private spending on education (indicator). https://doi.org/10.1787/6e70bede-en (Accessed on 01 November 2021.)
} 
Proposition 3.5 The effect of an increase in parents' human capital level on the fertility rate depends on whether the human capital level is below or above a certain threshold value, $\tilde{h}_{t}$. It can be shown that the following conditions hold:

$$
\frac{\partial n_{i t}^{*}}{\partial h_{i t}}\left\{\begin{array}{l}
<0, \text { if } h_{i t}<\tilde{h}_{t}, \\
=0, \text { if } h_{i t}=\tilde{h}_{t}, \\
>0, \text { if } h_{i t}>\tilde{h}_{t} .
\end{array}\right.
$$

Proof It can be verified by considering the comparative statics of (17) that $\frac{\partial n_{i t}^{*}}{\partial h_{i t}} \gtrless 0$. See Appendix A.5 for details.

As the equation $\frac{\partial n_{i t}^{*}}{\partial h_{i t}}=0$, stemming from (18), is based on a nonlinear function of $h_{i t}$, we cannot solve it explicitly for the threshold value of $\tilde{h}_{t}$. However, we solve the equation numerically for given parameter values in the calibration section of the paper. This result shows that our model captures the inverse J-shaped incomefertility relationship at the individual level as demonstrated by Futagami and Konishi (2019), Hazan and Zoabi (2015), and Ohinata and Varvarigos (2019), and Siegel (2017). However, we show that this rebound is not determined purely by the income effect as the authors above found; instead, the rebound occurs when the income effect dominates the child survival effect (the details are in Appendix A.3.5). The main point is that only agents with sufficiently high human capital can afford fertility rates increasing with the level of their human capital. In addition, the structural changes that reduce child-rearing costs (captured as a decrease in childcare cost function $\psi$ ) magnify the positive income effect on fertility. Only when agents with a positive income-fertility relationship stochastically dominate in the population, can we have a fertility rebound in the spirit of Day (2016). One can argue that with higher inequality levels, only a small fraction of the population experiences increasing fertility, the effect of which on average fertility would be more than offset by the decline in the fertility of the rest of the population. Given that inequality levels have been increasing in most of the advanced economies (Hoeller et al. 2013), it is not likely that this inequality effect on fertility rates is driving the overall fertility rebound. Thus, the effect of increasing human capital on overall fertility rates is not straightforward.

\subsection{A reversal of the decline in fertility rates}

Based on the findings of Hazan and Zoabi (2015) and Day (2016), and Siegel (2017), we infer that when the fall in the value of $\psi$ is due to social and economic structural changes, the fertility of the part of the population affected by these changes would increase. The same outcome is also established in our model; that is, it can be verified that

$$
\frac{\partial n_{i t}}{\partial \psi_{i t}} \frac{\partial \psi_{i t}}{\partial h_{i t}}>0 .
$$

Intuitively, such changes can lead to an increase in the benchmark fertility rates. Access to childcare services and the social change that leads to greater involvement of fathers in child-rearing can affect mostly the part of the population with high human 
capital levels. As women with high human and income levels naturally have higher social status, their fertility choices are more likely to influence social norms. If this hypothesis is true, then the increase in the fertility rates of women of this type can affect the social benchmark fertility (social norms). Thus, increases in the fertility of high-income women due to structural changes in childcare lead to an overall rise in fertility through fertility norm externalities.

The positive effect of fertility externalities would become noticeable only if this effect dominates other negative effects on fertility stemming from consumption and human capital externalities. Such an outcome is possible, as according to Proposition 3.1 and Proposition 3.2, at high benchmark levels of consumption and human capital, their marginal effect on fertility choice becomes negligible; thus, the effect of fertility externalities becomes dominant at high income levels. In light of this, we conclude that the combined effect of structural changes in child-rearing costs and social externalities on fertility choice is the main factor that explains the recent fertility rebound in high-income countries.

\section{Calibration of the model and simulation results}

In this section, we carry out a calibration analysis to establish whether our theoretical model can numerically replicate the documented evolution of average fertility rates and the rebound in fertility rates of high-income agents in a cross-section. High-income countries exhibit not only the demographic transition but have also experienced a rebound or stabilization in fertility rates. Therefore, it would be logical to test our model on data for high-income countries. That is, we verify whether the model can exhibit a steep decline in fertility rates at the low income levels (captured by the average human capital levels) and a rebound in fertility after a certain income threshold is reached.

To calibrate the fertility rate given by (17), we adopt the parameter values with some adjustment for the time cost per child, $\tau$, the impact of the level of parents' human capital on the level of children's human capital, $\beta_{1}$, the degree of altruism, $\alpha$, and the elasticity of substitution, $s$, from similar calibrations presented in the literature discussed below. We determine the values of the other parameters by calibrating them to target the initial average fertility values for the selected high-income countries. As the theoretical model operates with generations as time periods, we set a year value for the period in the model. We follow Deopke (2004) and set the length of a generation to 25 years.

The social externalities incorporated in the model require heterogeneity of agents in terms of their human capital levels. Thus, we approximate the initial distribution of human capital. Because income is distributed according to the log-normal distribution (Young 2011), and given that human capital and income have a linear relationship (in our model), we also adopt a log-normal distribution for human capital. For the initial mean of the distribution, we adopt a log of 6.74 years of female education which is found to be the average years of education in 1960 for selected high-income countries using World Bank data. To determine the standard deviation of the lognormal distribution of human capital, we follow Aitchison and Brown (1957) and 
Table 1 Parameter values used in the calibration

\begin{tabular}{lll}
\hline Parameters & Values & Comments \\
\hline$\tau$ & 0.075 & $\begin{array}{l}\text { de la Croix and Doepke (2004) } \\
\text { de la Croix and Doepke (2004), adjusted to match initial } \bar{h}_{t+1}\end{array}$ \\
$\theta$ & 0.115 & Córdoba et al. (2016), adjusted \\
$\beta_{1}$ & 0.97 & de la Croix and Doepke (2004), adjusted to match initial $\bar{h}_{t+1}$ \\
$\beta_{2}$ & 0.595 & match initial $\bar{h}_{t+1}$ and $n_{t}$ \\
$\rho$ & 0.21 & Córdoba and Ripoll (2019) \\
$\pi$ & 3.0 & match the survival rates \\
$\sigma$ & 0.14 & match the survival rates \\
$B_{0}$ & 0.25 & match the initial $\bar{h}_{t+1}$ and $n_{t}$ \\
$\zeta$ & 2.98 & match the initial $\bar{h}_{t+1}$ and $n_{t}$ \\
$\delta$ & $(-0.002)$ & match the initial fertility rate \\
$\varepsilon$ & 0.018 & match the initial fertility rate \\
$\chi$ & 0.53 & match the initial fertility rate \\
$v$ & 1.035 & match the initial fertility rate \\
$\zeta h$ & 0.65 & match the average Gini index for 1960 \\
\hline
\end{tabular}

Young (2011). Aitchison and Brown (1957) show that for log-normally distributed population income, the Gini coefficient is given by $G=2 N[\varsigma / \sqrt{2}]-1$, where $\varsigma$ is the standard deviation of the log of income. From The United Nations University World Institute for Development Economics Research (UNU-WIDER), the World Income Inequality Database (WIID), we obtain data for the Gini index and compute the standard deviation of the log of human capital as $\varsigma_{h}=\sqrt{2} N^{-1}[(G+1) / 2] .{ }^{15}$ The data on the Gini index is obtained. For the starting point in our calibration, we assume that $G=0.345$. We approximate this value based on the average value of the Gini index for Germany and the in 1960, and for Denmark in 1961 as only for these countries Gini values were available.

The parameter values for the calibrated model are summarized in Table 1. We use the time cost per child, $\tau=0.075$, which is borrowed from de la Croix and Doepke (2004). Importantly, de la Croix and Doepke (2004) emphasize that the elasticity $\theta$ of human capital with respect to education should not be set too high; otherwise, the fertility differentials will be inflated. In our case, we aim to keep the initial average human capital accumulation above the average level of human capital of the firstgeneration parents. Thus, the elasticity of human capital with respect to education is set at $\theta=0.115$ (de la Croix and Doepke (2004) used $\theta=0.16$ ). In the same manner, we set the parameter that captures the impact of the level of parents' human capital on the level of children's human capital, $\beta_{1}=0.595$. Similarly, the elasticity

\footnotetext{
${ }^{15}$ For details, see also Crow, E. L., and Shimizu, K. (Eds.). (1988). Log-normal distributions: Theory and applications (Vol. 88). New York.
} 
of children's human capital with respect to the average human capital of the parent generation is set to allow for decreasing returns to scale for the human capital accumulation process. Thus, we set $\beta_{2}=0.21$.

The value of the altruism parameter is selected as $\alpha=0.97$, which is not far from the range of $\alpha \in$ [0.90-0.95] used in Córdoba et al. (2016). The value of $\rho$ is calculated as $\rho=\frac{s}{s-1}$, where $s$ is the parameter of the elasticity of substitution. We use $s=1.5$, as in Córdoba and Ripoll (2019), and set $\rho=3$. $^{16}$

The average fertility rate captured in our model is the average of the completed fertility rates of the modeled adult agents in the current generation. Thus, the average completed cohort fertility rates observed in high-income countries are a more appropriate statistic for our model than the TFR. ${ }^{17}$ We also note that the TFR is a measure of period fertility and is based on the decisions of many different cohorts at a given point in time. Thus, the TFR may suffer from tempo effects and does not seem to reflect the fertility statistic implied by our model. ${ }^{18}$ Based on this logic, we set the following parameters to target the observed average cohort fertility rate in high-income economies, which was approximately equal to 2.24 in 1985.

We set the parameter values of consumption externalities, $\delta=0.018$, and fertility norms externalities, $\varepsilon=0.53$. The parameters capturing the childcare cost reduction through market services and husbands' involvement are set as follows: $\chi=1.035$ and $v=0.65$. This reduction in the time cost is applicable only to those who have a level of human capital exceeding the level of human capital in the childcare sector. The initial fertility norm $\bar{n}_{1}$ is assumed to be equal to 3.9 children, and the initial average consumption is assumed to be given by $\bar{c}_{1}=0.6 \bar{h}_{1}$.

In setting the values for the productivity coefficient of the human capital accumulation function $B_{0}$, we use the following rationale. Specifically, we tried to match the initial fertility rate and the human capital accumulation. We set $B_{0}=2.98$ to match the initial $\bar{h}_{t+1}$ and $n_{t}$. The parameter capturing the effect of the marginal total productivity of the education system on the average level of human capital is set, $\zeta=-0.002$. Thus, the marginal total productivity of the education system is decreasing in the average level of human capital. Given that with a greater and more complex knowledge stock, it is logical to expect that human capital accumulation would require greater marginal costs. The probability of child survival $\bar{\pi}$ and the elasticities of human capital ( $\sigma$ of the parent's human capital, $1-\sigma$, of the average human capital) are calibrated to match the observed survival rates. ${ }^{19}$ We start with a high average probability value of $0.95-0.97$ as we are targeting the child survival rates in high-income countries from the 1960 s and aim to get $\pi=1$ in the second-to-third periods.

\footnotetext{
${ }^{16}$ We also tried $s=3$ as in Jones and Schoonbroodt (2016), but this value did not let us achieve the targeted initial fertility rate.

17 For example, Albanesi and Olivetti (2014) and Bailey and Hershbein (2018), and Chabé-Ferret and Gobbi (2018) demonstrate that the observed fertility dynamics can be explained using cohort fertility.

${ }^{18}$ See Bongaarts and Feeney (1998) for the discussion of tempo and quantum effects in fertility.

${ }^{19}$ Data source: https://population.un.org/wpp2019/Download/Standard/Interpolated/.
} 
The time series plots for the simulated and observed fertility data are displayed in Fig. 4 and the dataset is given in Table 2. We parametrize the model by matching the simulated initial fertility rate with the observed initial cohort fertilit rate as discussed.

The comparison of the simulated fertility rates with the statistical data demonstrates that our model, for a feasible set of parameters, can simulate fertility rate dynamics that are consistent with the evolution of the observed CFRs. However, we admit that even with all the externalities incorporated and a quite ad hoc entry of market-based childcare services, we were not able to fully replicate the sharp decline in fertility rates observed in the data without having a rebound fertility rate that is lower than in the data. Thus, the simulated series shown in Fig. 4 closely matches the starting and rebound points in the data, but not the point at the end of the fertility decline. This implies that there are still some other factors that affect fertility choice that are not accounted for in the model.

The simulation results indicate that the model is not well suited for explaining the evolution of the TFRs. Although the simulated series show a pattern similar to

Table 2 Simulated and observed fertility rates in high-income countries

\begin{tabular}{llll}
\hline Year & Actual TFR & Actual CFR & Simulated CFR \\
\hline 1950 & 2.81 & & \\
1955 & 2.89 & & 2.72 \\
1960 & 2.98 & & \\
1965 & 2.85 & & \\
1970 & 2.50 & & \\
1975 & 2.13 & 2.49 & \\
1980 & 1.87 & 2.24 & \\
1985 & 1.73 & 2.10 & \\
1990 & 1.67 & 1.98 & \\
1995 & 1.63 & 1.94 & \\
2000 & 1.60 & 1.89 & 1.93 \\
2005 & 1.67 & 1.83 & 1.82 \\
2010 & 1.70 & 1.80 & \\
2015 & 1.80 & 1.84 & \\
2020 & & 1.82 & \\
2035 & & & \\
2060 & & & \\
2085 & & & \\
2105 & & & \\
\hline
\end{tabular}

The average TFR for high-income countries over 1960-2035. The following countries are included: see Appendix A.6

Source of data: TFR is from United Nations, Department of Economic and Social Affairs, Population Division (2019). The CFRs are from the Human Fertility Database (2021). The actual CFRs for 2035 are found as a linear extrapolation of the data. The simulated CFRs are given in 25-year intervals 
that of the TFR, the model cannot produce the sharp decline manifested by the TFR. This deviation most likely stems from the tempo effects in the TFR, which are not captured in our simple OLG model.

The reasonable consistency of the actual CFR data with the computed fertility rates using the simulated model allows us to conclude that the model with social externalities adequately describes the evolution of completed fertility. In addition, the model captures the rebound (stabilization) of fertility rates in the long run. It appears that the demographic transition ends as soon as the countries reach certain development levels; after that, fertility rates gradually rebound (stabilize) as the income levels increase.

As shown in Fig. 5, we also evaluate whether the model can generate an inverse J-shaped fertility-income relationship in the cross-section of agents with different human capital levels. In particular, we tried to replicate the curves for 1990 and 2010 given in Fig. 1. The model yields fertility rates that decline with the education levels, when we use a distribution of human capital with an average of nine years of education. The simulated curve is similar to the curve of the relationship between education and fertility in 1990 observed in the USA. When we use a distribution of human capital with an average of 12 years of education, we obtain an inverse J-shaped fertility-human capital relationship as the curve for 2010 in the USA. Therefore, the model captures the possibility of rising fertility of the high-income agents observed in the USA (see Fig. 1). Intuitively, the cross-section simulation can also be used to explain the differences among countries in terms of their fertility. Such simulation shows, the differences among countries in terms of average human capital levels and their distribution across agents, as well as social externalities and childcare costs, contribute to agents' fertility levels; these factors contribute to the changes in average fertility rates.

As a related issue, using (A15), we also find a numerical solution for $\tilde{h}$. That is, we determine the threshold value for human capital that divides agents into two groups: (1) agents whose fertility declines when their human capital increases and (2) agents whose fertility rises when their human capital increases. For the same parameter values used in high-income countries, we find that the threshold education is equal to 14.1 years; that is, agents with more than 14.1 years of education can have an increase in fertility rates when their human capital increases further.

\subsection{Sensitivity analysis}

We conduct a sensitivity analysis to evaluate the role of the externalities and other new mechanisms incorporated into the model. We run the analyses by shutting off these channels one at a time and running the simulations of the model using the given set of parameters in Table 1 for the dynamic case and the values given in Appendix A.7 for the cross-section case. We test the sensitivity of the model to the exclusion of a given factor by assuming $\psi=1$ and $\pi=1$ or assuming the corresponding elasticity of the factor is equal to zero as $\epsilon=0$, and $\delta=0$. We illustrate the restricted simulations against the benchmark simulations based on the model by including all the factors (see Fig. 6). 

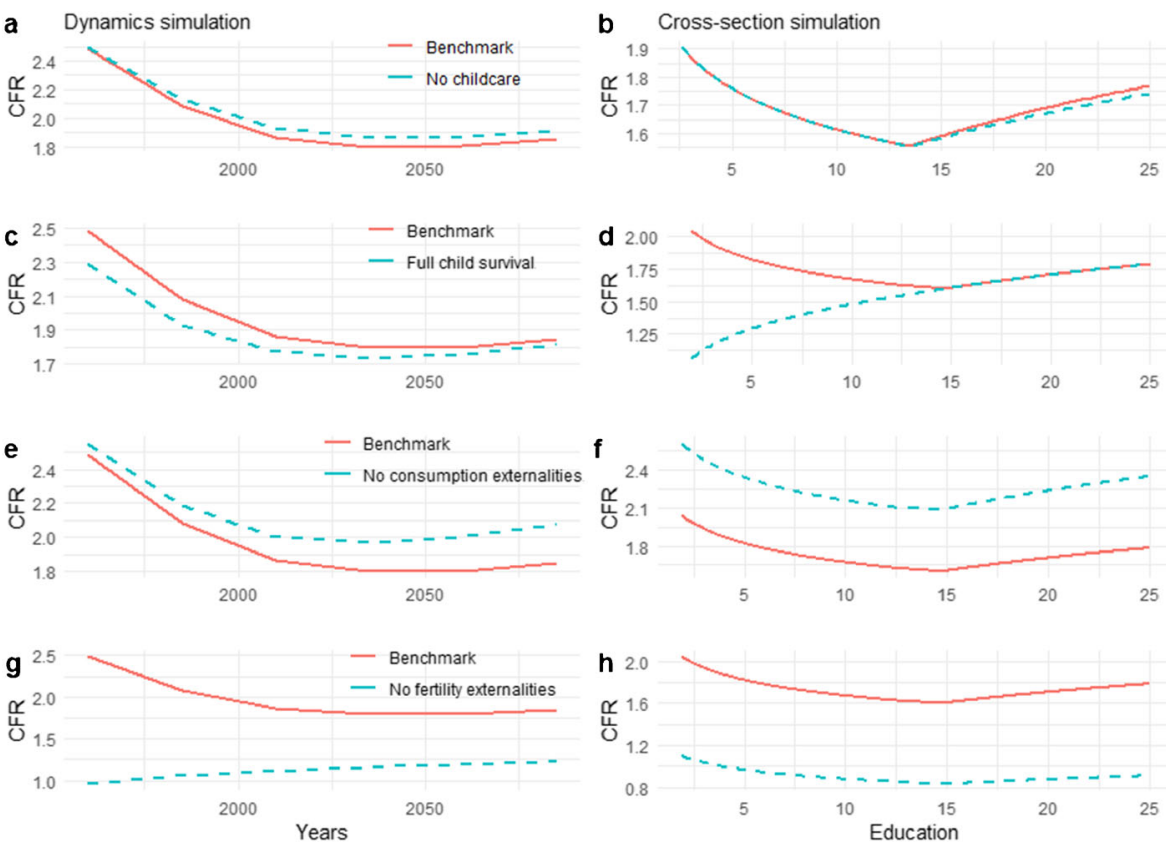

Fig. 6 The sensitivity analyses: the benchmark vs. restricted cases

Shutting off the channel of the childcare $(\psi=1)$ makes the evolution of fertility rates smoother (see Fig. 6, panels $a$ and $b$ ). With this simplification of the model, the simulated decline in fertility rates is lower, and the rebound is also less pronounced than otherwise. ${ }^{20}$ The cross-sectional simulations highlight this effect: In the absence of market-based childcare services, fertility rates of higher-income agents increase more slowly than they would have in its presence. Thus, ignoring childcare costs would lead to underestimation of the rebound at the aggregate level, although for the parametrization we used, its impact appears weak.

The probability of survival (i.e., assuming $\pi=1$ ) was not a significant factor for the overall dynamics of the model (see Fig. 6, panels $c$ and $d$ ). It is reasonable, as high-income countries had high child survival rates in the last few decades. The probability of survival has some effect only in earlier periods, when the survival rate was below unity for low-income agents. We confirm this point with the simulations based on a cross-section of agents. These simulations show that the probability of survival is a crucial factor as long as it is not equal to unity for all the agents. For a small proportion of agents with a significant rate of child mortality, the curve of the fertility-income relationship becomes different when the effect of survival is ignored.

Analysis of the empirical role of social externalities in fertility rates provides the following findings. In particular, the consumption externalities explain some of the

\footnotetext{
${ }^{20}$ However, the effect of exogenous changes in $\psi$ depends on the marginal effect of education spending given by parameter $\theta$. We can verify it using (A11) in Appendix A.3.5. For example, for significantly high values of $\theta$, it is possible to obtain a greater decline in fertility rates over time.
} 
sharp decrease in the fertility rates at the beginning of the period we considered (see Fig. 6, panel $e$ and $f$ ). When we shut down this channel, by setting $\delta=0$, the simulated cross-sectional fertility rates are higher for all human capital levels. In the dynamic case, we cannot replicate the initial decline in the data. We obtain a significantly shallower simulated decline. In addition, without the consumption externalities effect, the rebound in fertility rates becomes higher, which results in a sharper increase in fertility rates than observed in the data. As expected, shutting down the effect of fertility externalities, by setting $\epsilon=1$, results in much lower fertility rates than the observed values (see Fig. 6, panels $g$ and $h$ ). It appears that fertility norms play a significant role in the evolution of the overall fertility rates. In sum, the experiments confirm the structure of the theoretical model. We demonstrate that all three externalities are critical in the evolution of fertility choice over time. Thus, it seems necessary to account for these externalities in explaining agents' fertility.

\section{Conclusion}

This paper develops an explanation for the so-called inverse J-shaped relationship between fertility and per capita income levels. We extend the standard fertility choice model by simultaneously accounting for endogenous childcare costs, child survival, and social externalities stemming from fertility norms, average human capital, and consumption. Using the extended fertility choice model, we find that at lower benchmark levels of human capital and consumption, their external effect on fertility is negative and significant. The effect of an increase in child survival rates is also negative. All these effects on fertility complement the "quality-quantity trade-off" effect and result in the steep fall in fertility rates during the demographic transition. In addition, the falling benchmark fertility rates, through fertility externalities, magnify the decrease in the average fertility rates. On the other hand, at high benchmark levels, the marginal external effects of human capital and consumption on fertility become negligible. Under such circumstances, the income effect and social and structural changes in childcare lead to growth in benchmark fertility rates. The increase in benchmark fertility rates raises average fertility rates through fertility norm externalities. This outcome explains the observed reversal of the decline in fertility rates in high-income countries in recent years.

The simulations based on the calibrated theoretical model demonstrate that the model emulates the observed evolution of the average cohort fertility rates for highincome economies. Specifically, the model dynamically simulates an initial decline in fertility, which then changes into a reversal (or stabilization) after a certain income threshold is reached. Furthermore, as social externalities, childcare, and child survival differentiation stem from the heterogeneity of agents, we conduct cross-sectional simulations of the model. We find that the model repproduce the inverse J-shaped fertility-income relationship in the cross-section of agents with different human capital levels observed in high-income countries. In addition, we conduct a sensitivity analysis by separately shutting off the externalities, childcare, and child survival channels in the model and running the simulations using the calibrated parameters. 
The results show that all three externalities (fertility norms, average human capital, and consumption), childcare, and surviving child rates have significant roles in the evolution of fertility choice over time. Thus, ignoring these factors in explaining agents' fertility fails to provide a full explanation for the fertility evolution. Overall, by analyzing a richer but tractable preference structure, this study provides new insights into agents' fertility choice and thus enhances understanding of the evolution of fertility.

\section{Appendix. Proofs}

\section{A.1 A solution of the model in Section 2.5}

The agent's optimization problem can be solved by maximizing the following Lagrangian:

$$
\begin{aligned}
L= & \gamma\left[\alpha\left(\bar{c}_{t}^{-\delta} c_{i t}\right)^{\rho}+(1-\alpha)\left(B_{t} \bar{n}_{t}^{-\varepsilon}\left(\bar{h}_{t}^{\beta_{2}} h_{i t}^{\beta_{1}}\right)^{1-\theta} e_{i t}^{\theta} \pi_{i t} n_{i t}\right)^{\rho}\right]^{\frac{1}{\rho}}+ \\
& +\lambda\left[h_{i t}\left(1-\tau \psi_{i t} n_{i t}\right)-e_{i t} n_{i t}-c_{i t}\right] .
\end{aligned}
$$

The first-order conditions are written as follows:

$$
\begin{aligned}
\frac{\partial L}{\partial c}= & \frac{\gamma}{\rho}\left[\alpha\left(\bar{c}_{t}^{-\delta} c_{i t}\right)^{\rho}+(1-\alpha)\left(B_{t} \bar{n}_{t}^{-\varepsilon}\left(\bar{h}_{t}^{\beta_{2}} h_{i t}^{\beta_{1}}\right)^{1-\theta} e_{i t}^{\theta} \pi_{i t} n_{i t}\right)^{\rho}\right]^{\frac{1-\rho}{\rho}} \times \\
& \times\left(\alpha \rho \bar{c}_{t}^{-\delta \rho} c_{i t}^{\rho-1}\right)-\lambda=0 . \\
\frac{\partial L}{\partial n}= & \frac{\gamma}{\rho}\left[\alpha\left(\bar{c}_{t}^{-\delta} c_{i t}\right)^{\rho}+(1-\alpha)\left(B_{t} \bar{n}_{t}^{-\varepsilon}\left(\bar{h}_{t}^{\beta_{2}} h_{i t}^{\beta_{1}}\right)^{1-\theta} e_{i t}^{\theta} \pi_{i t} n_{i t}\right)^{\rho}\right]^{\frac{1-\rho}{\rho}} \times \\
& \left((1-\alpha) \rho n_{i t}^{\rho-1}\left(B_{t} \bar{n}_{t}^{-\varepsilon}\left(\bar{h}_{t}^{\beta_{2}} h_{i t}^{\beta_{1}}\right)^{1-\theta} \pi_{i t} e_{i t}^{\theta}\right)^{\rho}\right)-\lambda\left[h_{i t} \tau \psi_{i t}+e_{i t}\right]=0 . \\
\frac{\partial L}{\partial e}= & \frac{\gamma}{\rho}\left[\alpha\left(\bar{c}_{t}^{-\delta} c_{i t}\right)^{\rho}+(1-\alpha)\left(B_{t} \bar{n}_{t}^{-\varepsilon}\left(\bar{h}_{i t}^{\beta_{2}} h_{i t}^{\beta_{1}}\right)^{1-\theta} e_{i t}^{\theta} \pi_{t} n_{i t}\right)^{\rho}\right]^{\frac{1-\rho}{\rho}} \times \\
& \left((1-\alpha) \rho \theta e_{i t}^{\theta \rho-1}\left(B_{t} \bar{n}_{t}^{-\varepsilon}\left(\bar{h}_{i t}^{\beta_{2}} h_{i t}^{\beta_{1}}\right)^{1-\theta} \pi_{i t} n_{i t}\right)^{\rho}\right)-\lambda n_{i t}=0 . \quad(\mathrm{A} 4)
\end{aligned}
$$

Solving the first-order condition equations, we find:

$$
n_{i t}^{*}=\frac{e_{i t}^{*}=\frac{\theta h_{i t} \tau \psi_{i t}}{h_{i t}\left(\frac{h_{i t} \tau \psi}{1-\theta} \alpha\right)^{\frac{1}{\rho-1}}}}{\left[(1-\alpha)\left(B_{t} \bar{n}_{t}^{-\varepsilon}\left(\bar{h}_{t}^{\beta_{2}} h_{i t}^{\beta_{1}}\right)^{1-\theta} \pi_{i t}\left(\frac{\theta h_{i t} \tau \psi_{i t}}{1-\theta}\right)^{\theta}\right)^{\rho}\right]^{\frac{1}{\rho-1}} \bar{c}_{t}^{\frac{\delta \rho}{\rho-1}}+\left[\left(\frac{h_{i t} \tau \psi_{i t}}{1-\theta}\right)^{\rho} \alpha\right]^{\frac{1}{\rho-1}}} .
$$


Given that the labor supply is inelastic, and the utility function is concave, the budget constraint is binding:

$$
c_{i t}^{*}=h_{i t}\left(1-\tau \psi_{i t} n_{i t}^{*}\right)-e_{i t}^{*} n_{i t}^{*} .
$$

\section{A.2 Proof of Proposition 3.1}

Proposition 3.1 can be verified by the following: Take the first-order derivative of (A6) with respect to $\bar{c}_{t}$ and obtain

$$
\begin{array}{r}
\frac{\partial n^{*}}{\partial \bar{c}}=\frac{-\delta \rho}{(\rho-1) \bar{c}_{t}} \times \\
\times \frac{h_{i t}\left[\left(\frac{h_{i t} \tau \psi_{i t}(1-\alpha) \alpha}{1-\theta}\right)\left(B_{t} \bar{n}_{t}^{-\varepsilon}\left(\bar{h}_{t}^{\beta_{2}} h_{i t}^{\beta_{1}}\right)^{1-\theta} \pi_{i t}\left(\frac{\theta h_{i t} \tau \psi_{i t}}{1-\theta}\right)^{\theta}\right)^{\rho}\right]^{\frac{1}{\rho-1}} \bar{c}_{t}^{\frac{-\delta \rho}{\rho-1}}}{\Pi^{2}} .
\end{array}
$$

For brevity, we denote the numerator of (A6) as $\Pi$. As $\frac{-\delta \rho}{\rho-1}<0$ due to $\rho>1$, while the other terms are positive, $\frac{\partial n^{*}}{\partial \bar{c}}<0$ holds. It can be verified that the second term of (A8),

$$
\frac{h_{i t}\left[\left(\frac{h_{i t} \tau \psi_{i t}(1-\alpha) \alpha}{1-\theta}\right)\left(B_{t} \bar{n}_{t}^{-\varepsilon}\left(\bar{h}_{t}^{\beta_{2}} h_{i t}^{\beta_{1}}\right)^{1-\theta} \pi_{i t}\left(\frac{\theta h_{i t} \tau \psi_{i t}}{1-\theta}\right)^{\theta}\right)^{\rho}\right]^{\frac{1}{\rho-1}} \bar{c}_{t}^{\frac{-\delta \rho}{\rho-1}}}{\Pi^{2}}<n_{i t}^{*},
$$

thus, is bounded from above. However, as $\bar{c}_{t} \rightarrow \infty, \frac{1}{\bar{c}_{t}} \rightarrow 0$; thus,

$$
\lim _{\bar{c}_{t} \rightarrow \infty} \frac{\partial n_{i t}^{*}}{\partial \bar{c}_{t}} \rightarrow 0 .
$$

That is, at relatively high levels of $\bar{c}_{t}$, the marginal effect of consumption externalities on fertility diminishes.

\section{A.3 Proof of Proposition 3.2}

Take the first-order derivative of the (A6) with respect to $\bar{h}_{t}$ and obtain

$$
\begin{aligned}
& \frac{\partial n_{i t}^{*}}{\partial \bar{h}_{t}}= \\
-\frac{\rho}{(\rho-1) \Pi^{2}} & \left(h_{i t}\left(\frac{h_{i t} \tau \psi_{i t}}{1-\theta} \alpha\right)^{\frac{1}{\rho-1}}\right)\left[(1-\alpha)\left(\bar{n}_{t}^{-\varepsilon} h_{i t}^{\beta_{1}(1-\theta)}\left(\frac{\theta h_{i t} \tau \psi_{i t}}{1-\theta}\right)^{\theta}\right)^{\rho}\right]^{\frac{1}{\rho-1}} \times \\
& \times B_{t}^{\frac{\rho}{\rho-1}} \bar{c}_{t}^{\frac{\delta \rho}{\rho-1}} \pi_{i t}^{\frac{\rho}{\rho-1}} \bar{h}_{t}^{\frac{\rho \beta_{2}(1-\theta)}{\rho-1}}\left[\frac{1}{B_{t}} \frac{\partial B_{t}}{\partial \bar{h}_{t}}+\frac{\delta}{\bar{c}_{t}} \frac{\partial \bar{c}_{t}}{\partial \bar{h}_{t}}+\frac{(1-\theta) \beta_{2}}{\bar{h}}+\frac{1}{\pi} \frac{\partial \pi_{i t}}{\partial \bar{h}_{t}}\right] .
\end{aligned}
$$

We recall that $B_{t}=B_{0} \bar{h}_{t}^{\xi}$, and $\pi_{i t}=\underline{\pi} \bar{h}_{t}^{1-\sigma} h_{i t}^{\sigma}$. Thus, we can find that $\frac{1}{B_{t}} \frac{\partial B_{t}}{\partial \bar{h}_{t}}=\frac{\xi}{\bar{h}_{t}}$ and $\frac{1}{\pi} \frac{\partial \pi_{i t}}{\partial \bar{h}_{t}}=\frac{(1-\sigma) \underline{\pi} \bar{h}_{t}^{1-\sigma} h_{i t}^{\sigma}}{\bar{h}_{t} \underline{\pi} \bar{h}_{t}^{1-\sigma} h_{i t}^{\sigma}}=\frac{1-\sigma}{\bar{h}_{t}}$. In addition, assuming that the 
average consumption is related to the average income through the propensity to consume, as $\bar{c}_{t}=p \bar{h}_{t}$, we also can write that $\frac{\delta}{\bar{c}_{t}} \frac{\partial \bar{c}_{t}}{\partial \bar{h}_{t}}=\frac{\delta p}{\bar{h}_{t}}$. It can be verified that $\frac{1}{\bar{h}_{t}}\left(\xi+\delta p+(1-\theta) \beta_{2}+1-\sigma\right)>0$, as $\left(\frac{\rho}{\rho-1}\right)>0$ by definition, and thus, $\frac{\partial n_{i t}}{\partial \bar{h}_{t}}<0$. However, when $\bar{h}_{t} \rightarrow \infty$, then $\frac{1}{\bar{h}_{t}} \rightarrow 0$. Therefore, we can conclude that

$$
\lim _{\bar{h}_{t} \rightarrow \infty} \frac{\partial n_{i t}^{*}}{\partial \bar{h}_{t}}=0 .
$$

That is, at relatively high levels of $\bar{h}_{t}$, the marginal effect of human capital externalities on fertility diminishes.

\section{A.4 Proof of Proposition 3.3}

Proposition 3.3 can be verified by showing that $\frac{\partial n_{i t}^{*}}{\partial \bar{n}_{t}}>0$. We obtain $\frac{\partial n^{*}}{\partial \bar{n}}$ using (A6),

$$
\begin{array}{r}
\frac{\partial n^{*}}{\partial \bar{n}}=\frac{\varepsilon \rho}{(\rho-1) \bar{n}_{t}} \times \\
\times \frac{h_{i t}\left[\left(\frac{h_{i t} \tau \psi_{i t}(1-\alpha) \alpha}{1-\theta}\right)\left(B_{t} \bar{c}_{t}^{-\delta}\left(\bar{h}_{t}^{\beta_{2}} h_{i t}^{\beta_{1}}\right)^{1-\theta} \pi_{i t}\left(\frac{\theta h_{i t} \tau \psi_{i t}}{1-\theta}\right)^{\theta}\right)^{\rho}\right]^{\frac{1}{\rho-1}} \bar{n}_{t}^{\frac{-\varepsilon \rho}{\rho-1}}}{\Pi^{2}} .
\end{array}
$$

It can be verified that the sign of $\frac{\partial n^{*}}{\partial \bar{n}}$ depends on the sign of the term $\frac{\rho \varepsilon}{\rho-1}$. Since $\rho>1, \frac{\rho \varepsilon}{\rho-1}>0$, therefore, $\frac{\partial n^{*}}{\partial \bar{n}}>0$.

\section{A.5 Proof of Proposition 3.5}

Let us re-arrange (17) and simplify as follows:

$$
n_{i t}^{*}=\frac{1}{\Gamma \psi_{i t}^{\frac{\theta \rho-1}{\rho-1}} \pi_{i t}^{\frac{\rho}{\rho-1}} h_{i t}^{\zeta}+\frac{\psi_{i t} \tau}{1-\theta}},
$$

where $\Gamma \equiv\left[\frac{(1-\alpha)}{\alpha} \bar{c}_{t}^{\rho \delta}\left(B_{t} \bar{n}_{t}^{-\varepsilon}\right)^{\rho} \bar{h}_{t}^{\beta_{2} \rho(1-\theta)} \theta^{\theta \rho}\left(\frac{\tau}{1-\theta}\right)^{\theta \rho-1}\right]^{\frac{1}{\rho-1}}>0$, and $\zeta \equiv$ $\frac{\rho\left(1-\beta_{1}\right)(\theta-1)}{\rho-1}<0$.

By taking the first-order derivative of (A11) with respect to $h_{i t}$, we obtain

$$
\frac{\partial n_{i t}^{*}}{\partial h_{i t}}=\frac{-\Gamma \psi_{i t}^{\frac{\theta \rho-1}{\rho-1}} \pi_{i t}^{\frac{\rho}{\rho-1}} h_{i t}^{\zeta}\left(\frac{\theta \rho-1}{\rho-1} \psi_{i t}^{-1} \frac{\partial \psi_{i t}}{\partial h_{i t}}+\zeta h_{i t}^{-1}+\frac{\rho}{\rho-1} \pi_{i t}^{-1} \frac{\partial \pi_{i t}}{\partial h_{i t}}\right)-\frac{\tau}{(1-\theta)} \frac{\partial \psi_{i t}}{\partial h_{i t}}}{\left[\Gamma \psi_{i t}^{\frac{\theta \rho-1}{\rho-1}} \pi_{i t}^{\frac{\rho}{\rho-1}} h_{i t}^{\zeta}+\frac{\psi_{i t} \tau}{1-\theta}\right]^{2}}
$$

where $\zeta \equiv \frac{\rho\left(1-\beta_{1}\right)(\theta-1)}{\rho-1}<0$. One can find that the effect of the individual human capital depends on the values of $\frac{\partial \psi_{i t}}{\partial h_{i t}}$ and $\frac{\partial \pi_{i t}}{\partial h_{i t}}$ that are determined by the individual's relative standing in terms of the human capital level. We have two cases with respect to childcare time costs: (i) The agent cannot use market-based childcare services; 
thus, $\psi_{i t}=1$, and $\frac{\partial \psi_{i t}}{\partial h_{i t}}=0$. (ii) The agent can use market-based childcare services, and thus, $\psi_{i t}=\chi \frac{\underline{h}_{t}}{h_{i t}^{v}}<1$, and $\frac{\partial \psi_{i t}}{\partial h_{i t}}=-\chi v \frac{\underline{h}_{t}}{h_{i t}^{1+v}}<0$. We also have two cases with respect to the child survival probability: Either $\pi_{i t}=1$, and thus, $\frac{\partial \pi_{i t}}{\partial h_{i t}}=0$, or $\pi_{i t}<1$, and thus, $\frac{\partial \pi_{i t}}{\partial h_{i t}}=\sigma \underline{\pi} \bar{h}_{t}^{1-\sigma} h_{i t}^{\sigma-1}>0$.

Let us consider case (i). It is expected that agents with relatively low human capital have to look after their children themselves, only and they may have lower child survival probability. In addition, this type of agent, due to low levels of human capital, is expected to have child survival rates that are less than unity, $\pi_{i t}<1$. Then, for this type of agent, the effect of individual human capital is written explicitly as follows:

$$
\frac{\partial n_{i t}^{*}}{\partial h_{i t}}=\frac{-\Gamma \pi_{i t}^{\frac{\rho}{\rho-1}} h_{i t}^{\zeta}\left(\frac{\zeta}{h_{i t}}+\frac{\rho}{\rho-1} \frac{\sigma}{h_{i t}}\right)}{\left[\Gamma \psi_{i t}^{\frac{\theta \rho-1}{\rho-1}} \pi_{i t}^{\frac{\rho}{\rho-1}} h_{i t}^{\zeta}+\frac{\psi_{i t} \tau}{1-\theta}\right]^{2}}=\frac{-\Gamma\left(\underline{\pi} \bar{h}_{t}^{\sigma_{2}}\right)^{\frac{\rho}{\rho-1}}\left(\zeta+\frac{\sigma_{1} \rho}{\rho-1}\right) h_{i t}^{\omega}}{\left[\Gamma\left(\chi \underline{\underline{h}_{t}}\right)^{\frac{\theta \rho-1}{\rho-1}}\left(\underline{\pi} \bar{h}_{t}^{\sigma_{2}}\right)^{\frac{\rho}{\rho-1}} h_{i t}^{\zeta+\frac{\sigma_{1} \rho}{\rho-1}}+\frac{\chi \underline{h}_{t} \tau}{h_{i t}^{\nu}(1-\theta)}\right]^{2}},
$$

where we substitute for $\psi_{i t}=\chi \frac{\underline{h}_{t}}{h_{i t}^{v}}$, and $\pi_{i t}=\underline{\pi} \bar{h}_{t}^{1-\sigma} h_{i t}^{\sigma}, \frac{\partial \pi_{i t}}{\partial h_{i t}}=\sigma \underline{\pi}\left(\frac{\bar{h}_{t}}{h_{i t}}\right)^{1-\sigma}$; recalling that $\zeta \equiv \frac{\rho\left(1-\beta_{1}\right)(\theta-1)}{\rho-1}$, we also write $\omega=\frac{\sigma \rho+\rho\left(1-\beta_{1}\right)(\theta-1)}{\rho-1}-1$.

The sign of $\frac{\partial n_{i t}^{*}}{\partial h_{i t}}$ depends on what is greater: the income effect, $\zeta h_{i t}^{-1}<0$ as $\zeta<0$, or the effect of survival, $\frac{\rho}{\rho-1} \pi_{t}^{\frac{1}{\rho-1}} \frac{\partial \pi_{i t}}{\partial h_{i t}}=h_{i t}^{-1} \frac{\sigma \rho}{\rho-1}>0$ as $\rho>1$. By construction, $-\Gamma\left(\underline{\pi} \bar{h}_{t}^{1-\sigma}\right)^{\frac{\rho}{\rho-1}} h_{i t}^{\omega}<0$. Thus, if at low-income levels the survival effect dominates the income effect, then an increase in human capital leads to a decrease in the fertility rate. $^{21}$ Specifically, one can verify that growth in the level of their human capital leads to a decrease in fertility rates if

$$
\zeta+\frac{\sigma \rho}{\rho-1}=\frac{\rho\left(1-\beta_{1}\right)(\theta-1)}{\rho-1}+\frac{\sigma \rho}{\rho-1}>0 .
$$

Thus, in this case, (A13) implies that $\frac{\partial n_{i t}^{*}}{\partial h_{i t}}<0$. If the survival effect dominates the income effect, we have

$$
\zeta+\frac{\sigma \rho}{\rho-1}=\frac{\rho\left(1-\beta_{1}\right)(\theta-1)}{\rho-1}+\frac{\sigma \rho}{\rho-1}<0 ;
$$

thus, (A13) implies that $\frac{\partial n_{i t}^{*}}{\partial h_{i t}}>0$.

Now, let us consider case (ii), when agents possess a high level of human capital, they can afford childcare services; thus, $\psi<1$. Therefore, for these agents, we have $\frac{\partial \psi}{\partial h_{i t}}=-\chi \nu \frac{h_{t}}{h_{i t}^{v+1}}<0$. It is also probable to expect that the child survival rates for

\footnotetext{
${ }^{21}$ This result is in line with Kalemli-Ozcan (2002), who establishes that the quality-quantity trade-off occurs when agents' human capital is relatively low, and child mortality is endogenous. That is, at lowincome levels, the survival effect dominates the income effect; thus, an increase in human capital leads to a decrease in the fertility rate.
} 
these agents reach the maximum level; thus, $\pi \approx 1$ and $\frac{\partial \pi}{\partial h_{i t}} \approx 0$. Then, for this type of agent, the effect of individual human capital is written explicitly as follows:

$$
\begin{aligned}
\frac{\partial n_{i t}^{* *}}{\partial h_{i t}}=\frac{-\Gamma \psi^{\frac{\theta \rho-1}{\rho-1}} h_{i t}^{\zeta}\left(\frac{\theta \rho-1}{\rho-1} \psi_{i t}^{-1} \frac{\partial \psi_{i t}}{\partial h_{i t}}+\zeta h_{i t}^{-1}\right)-\frac{\tau}{1-\theta} \frac{\partial \psi_{i t}}{\partial h_{i t}}}{\left[\Gamma \psi_{i t}^{\frac{\theta \rho-1}{\rho-1}} \pi_{i t}^{\frac{\rho}{\rho-1}} h_{i t}^{\zeta}+\frac{\psi_{i t} \tau}{1-\theta}\right]^{2}}= \\
=\frac{-\Gamma\left(\chi \frac{\underline{h}_{t}}{\bar{h}_{i t}^{\nu}}\right)^{\frac{\theta \rho-1}{\rho-1}} h_{i t}^{\zeta-1}\left(\frac{\left[-v \chi(\rho \theta-1)+\rho\left(1-\beta_{1}\right)(\theta-1)\right]}{\rho-1}\right)+\frac{\tau v \chi}{1-\theta} \frac{\underline{h}_{t}}{h_{i t}^{v+1}}}{\left[\Gamma\left(\chi \frac{\underline{h}_{t}}{h_{i t}^{\nu}}\right)^{\frac{\theta \rho-1}{\rho-1}}\left(\underline{\pi} \bar{h}_{t}^{1-\sigma}\right)^{\frac{\rho}{\rho-1}} h_{i t}^{\zeta+\frac{\sigma \rho}{\rho-1}}+\frac{\chi \underline{h}_{t} \tau}{h_{i t}^{\nu}(1-\theta)}\right]^{2}},
\end{aligned}
$$

where we make similar substitutions as in the case of (A13). It is clear that the sign of $\frac{\partial n_{i t}^{* *}}{\partial h_{i t}}$ depends on the sign of the term $\left[-v \chi(\rho \theta-1)+\rho\left(1-\beta_{1}\right)(\theta-1)\right]$. As $\rho>1$, $\beta_{1}<1$, and $\theta<1$, we can verify that $\left[-v \chi(\rho \theta-1)+\rho\left(1-\beta_{1}\right)(\theta-1)\right]<0$ strictly, as soon as $\rho \theta-1>0$. Even if $\rho \theta-1<0$, for a feasible range of parameter values, $\left[-v \chi(\rho \theta-1)+\rho\left(1-\beta_{1}\right)(\theta-1)\right]<0$ holds. This implies that $\frac{\partial n_{i t}^{* *}}{\partial h_{i t}}>0$ is feasible.

In light of the discussion given above, we conclude that $\frac{\partial n_{i t}^{*}}{\partial h_{i t}} \gtrless 0$ in general. The cut-off condition is determined by $\frac{\partial n_{i t}^{*}}{\partial h_{i t}}=0$. Thus, we write this equation in the expanded form by substituting for $\psi_{i t}=\chi \frac{\underline{h}_{t}}{h_{i t}^{v}}$ and $\pi_{i t}=\underline{\pi} \bar{h}_{t}^{1-\sigma} h_{i t}^{\sigma}$ :

$-\Gamma\left(\chi \frac{\underline{h}_{t}}{h_{i t}^{\nu}}\right)^{\frac{\theta \rho-1}{\rho-1}}\left(\underline{\pi} \bar{h}_{t}^{1-\sigma} h_{i t}^{\sigma}\right)^{\frac{\rho}{\rho-1}} h_{i t}^{\zeta-1}\left(-\frac{\theta \rho-1}{\rho-1}+\zeta+\frac{\sigma \rho}{\rho-1}\right)+\frac{\tau \chi \nu}{1-\theta} \frac{\underline{h}_{t}}{h_{i t}^{v+1}}=0$.

By solving (A15) for the level of human capital, and denoting it $\tilde{h}$, we can write the following conditions:

$$
\frac{\partial n_{i t}^{*}}{\partial h_{i t}}\left\{\begin{array}{l}
<0, \text { if } h_{i t}<\tilde{h}, \\
=0, \text { if } h_{i t}=\tilde{h}, \\
>0, \text { if } h_{i t}>\tilde{h} .
\end{array}\right.
$$

Equation (A15), of course, cannot be solved analytically. However, we can solve it numerically by applying some realistic parameter values. The numerical solution is given in the simulation section.

\section{A.6 Country data in Fig. 4 and Table 2}

TFR data are used for Austria, Australia, Belgium, Canada, Denmark, Finland, France, Germany, Greece, Iceland, Ireland, Italy, Japan, Norway, the Netherlands, New Zealand, Portugal, Sweden, Switzerland, the UK, and the USA.

The average CFRs are obtained for Austria, Canada, Denmark, Finland, France, Germany, Iceland, Italy, Japan, the Netherlands, Portugal, Sweden, Switzerland, England, and the USA. 


\section{A.7 The parameter values used in additional simulations}

\section{The parameter values used in the simulation for Fig. 5}

For the case of $\bar{h}_{1}=12: \delta=0.1, B=2.2, \varepsilon=0.6, \bar{n}_{1}=3, \sigma_{1}=0.25, \sigma_{2}=0.75$, $\underline{\pi}=0.08, \theta=0.25, \alpha=0.85, \beta_{1}=0.8, \beta_{2}=0.2 \tau=0.075, v=0.65, \rho=3$.

For the case of $\bar{h}_{1}=9: \delta=0.015, B=3, \varepsilon=0.7, \bar{n}_{1}=2.9, \sigma_{1}=0.25$, $\sigma_{2}=.0 .75, \underline{\pi}=0.08, \theta=0.2, \alpha=0.85, \beta_{1}=0.84, \beta_{2}=0.16 \tau=0.075$, $v=0.75, \rho=3$.

\section{The parameter values used in the cross-section sensitivity analyses}

For the cross-section analysis, we use the parameter values $\bar{h}_{1}=12, \delta=0.1, B=$ $2.2, \varepsilon=0.6, \bar{n}_{1}=3, \sigma_{1}=0.25, \sigma_{2}=0.75, \underline{\pi}=0.08, \theta=0.25, \alpha=0.85$, $\beta_{1}=0.8, \beta_{2}=0.2, \tau=0.075, v=0.65, \rho=3$.

Acknowledgements We thank the editor, Gregory Ponthiere, and two anonymous referees for their helpful comments.

Funding Open Access funding enabled and organized by CAUL and its Member Institutions.

\section{Declarations}

Conflict of interest The authors declare no competing interests.

Open Access This article is licensed under a Creative Commons Attribution 4.0 International License, which permits use, sharing, adaptation, distribution and reproduction in any medium or format, as long as you give appropriate credit to the original author(s) and the source, provide a link to the Creative Commons licence, and indicate if changes were made. The images or other third party material in this article are included in the article's Creative Commons licence, unless indicated otherwise in a credit line to the material. If material is not included in the article's Creative Commons licence and your intended use is not permitted by statutory regulation or exceeds the permitted use, you will need to obtain permission directly from the copyright holder. To view a copy of this licence, visit http://creativecommons.org/licenses/by/4.0/.

\section{References}

Abel A (1990) Asset prices under habit formation and catching up with the Joneses. Am Econ Rev 80:3842

Abel A (1999) Risk premia and term premia in general equilibrium. J Monet Econ 43:3-33

Agarwal SV, Mikhed V, Scholnick B (2020) Peers' income and financial Distress:Evidence from lottery winners and neighboring bankruptcies. Rev Financ Stud 33(1):433-472

Aitchison J, Brown JAC (1957) The lognormal distribution. Cambridge University Press, Cambridge

Albanesi S, Olivetti C (2014) Maternal health and the baby boom. Quant Econ 5(2):225-269. https://doi.org/10.3982/QE315

Bailey MJ, Hershbein BJ (2018) US Fertility rates and childbearing in american economic history, 18002010. Oxford Handb Amer Econ History 1:75-100

Barro RJ, Becker GS (1989) Fertility choice in a model of economic growth. Econometrica 57(2):481-501 Becker GS, Lewis HG (1973) On the interaction between the quantity and quality of children. J Polit Econ 81(2):S279-S288 
Becker GS, Tomes N (1976) Child endowments and the quantity and quality of children. J Polit Econ 84(4):S143-S162

Bhattacharya J, Chakraborty S (2012) Fertility choice under child mortality and social norms. Econ Lett 115(3):338-341

Blackburn K, Cipriani GP (2002) A model of longevity, fertility and growth. J Econ Dyn Control 26(2):187-204

Bongaarts J, Sobotka T (2012) A demographic explanation for the recent rise in European fertility. Popul Dev Rev 38(1):83-120

Bongaarts J, Feeney G (1998) On the quantum and tempo of fertility. Popul Dev Rev 24(2):271-91

Campbell J, Cochrane J (1999) By force of habit:a consumption-based explanation of aggregate stock behavior. J Political Econ 107:205-251

Chabé-Ferret B, Gobbi P (2018) Economic uncertainty and fertility cycles:The case of the post-WWII baby boom. Working Papers ECARES 2018-19, ULB- Universite Libre de Bruxelles

Chen B-L, Hsu Y-S, Mino K (2015) Welfare implications and equilibrium indeterminacy in a two-sector growth model with consumption externalities. Macroecon Dyn 19:535-577

Cigno A, Rosati FC (1996) Jointly determined saving and fertility behaviour:Theory, and estimates for Germany, Italy, UK and USA. Eur Econ Rev 40(8):1561-1589

Clark A, Oswald A (1996) Satisfaction and comparison income. J Public Econ 61(3):359-381

Constantinides G (1990) Habit formation:a resolution of the equity premium puzzle. J Polit Econ 98:519_ 543

Cooper B, Garcia-Penalosa C, Funk P (2001) Status effects and negative utility growth. Econ J 111(473):642-665

Córdoba JC, Liu X, Ripoll M (2016) Fertility, social mobility and long run inequality. J Monetary Econ 77:103-124. "Inequality, Institutions, and Redistribution" held at the Stern School of Business, New York University, April 24-25, 2015

Córdoba JC, Ripoll M (2019) The elasticity of intergenerational substitution, parental altruism, and fertility choice. Rev Econ Stud 86(5):1935-1972

Dasgupta P (2000) Reproductive externalities and fertility behaviour. Eur Econ Rev 44(4):619-644

Day C (2016) Fertility and economic growth:The role of workforce skill composition and child care prices. Oxf Econ Pap 68(2):546-565

de la Croix D, Doepke M (2003) Inequality and growth:Why differential fertility matters. Am Econ Rev 93:1091-1113

de la Croix D, Doepke M (2004) Public versus private education when differential fertility matters. J Dev Econ 73(2):607-629

Deopke M (2004) Accounting for Fertility Decline During the Transition to Growth. J. of Econ Growth 9(3):347-383

Doepke M (2005) Child mortality and fertility decline:Does the Barro-Becker model fit the facts? J Popul Econ 18(2):337-366

Dominiak P, Lechman E, Okonowicz A (2015) Fertility rebound and economic growth. New evidence for 18 countries over the period 1970-2011. Equilibrium. Quart J Econ Econ Policy 10(1):91-112

Dupor B, Liu W-F (2003) Jealousy and equilibrium overconsumption. Am Econ Rev 93(1):423-428

Easterlin RA (1995) Will raising the incomes of all increase the happiness of all? J Econ Behav Organ 27(1):35-47

Fioroni T (2010) Child mortality and fertility:Public versus private education. J Popul Econ 23:73-97

Fisher W, Hof F (2000) Relative consumption, economic growth, and taxation. J Econ 72:241-262

Foreman-Peck J, Zhou P (2021) Fertility versus productivity:a model of growth with evolutionary equilibria. J Popul Econ 34:1073-1104. https://doi.org/10.1007/s00148-020-00813-2

Futagami K, Konishi K (2019) Rising longevity, fertility dynamics, and R\&D-based growth. J Popul Econ 32(2):591-620

Gali J (1994) Keeping up with the Joneses:consumption externalities, portfolio choice, and asset prices. J Money Credit Bank 26:1-8

Goldstein JR, Sobotka T, Jasilioniene A (2009) The end of "lowest-low" fertility? Popul Dev Rev 35(4):663-699

Goto H (2008) Social norms, inequality and fertility. Econ Bull 10(13):1-9

Hazan M, Zoabi H (2006) Does longevity cause growth? A theoretical critique. J Econ Growth 11(4):363376

Hazan M, Zoabi H (2015) Do highly educated women choose smaller families? Econ J 125(587):11911226 
Hirazawa M, Yakita A (2017) Labor supply of elderly people, fertility, and economic development. J Macroecon 51:75-96

Hoeller P, Joumard I, Koske I (2013) Income Inequality in OECD Countries. World Scientific

Human Fertility Database (2021) Max Planck Institute for Demographic Research (Germany) and Vienna Institute of Demography (Austria). Available at https://www.humanfertility.org (data downloaded on $5 / 10 / 2021)$

Jones LE, Schoonbroodt A (2016) Baby busts and baby booms:The fertility response to shocks in dynastic models. Rev Econ Dyn 22:157-178

Jones LE, Schoonbroodt A, Tertilt M (2010) Fertility Theories:Can they explain the negative FertilityIncome relationship? University of Chicago Press, pp 43-100

Kalemli-Ozcan S (2002) Does the mortality decline promote economic growth? J Econ Growth 7(4):411439

Kuhn P, Kooreman P, Soetevent A, Kapteyn A (2011) The effects of lottery prizes on winners and their Neighbors:Evidence from the dutch postcode lottery. Am Econ Rev 101(5):2226-2247

Lacalle-Calderon M, Perez-Trujillo M, Neira I (2017) Fertility and economic development:Quantile regression evidence on the inverse J-shaped pattern. Eur J Popul 33:1-31

Lanzieri G (2013) Towards a 'baby recession' In: Europe? Statistics in focus 13, Eurostat

Liu W-F, Turnovsky SJ (2005) Consumption externalities, production externalities, and long-run macroeconomic efficiency. J Public Econ 89(5-6):1097-1129

Luci A, Thévenon O (2011) Does economic development drive the fertility rebound in OECD countries? Popul Soc 481:1-4

Maruyama A, Yamamoto K (2010) Variety expansion and fertility rates. J Popul Econ 23(1):57-71

Mavropoulos G, Panagiotidis T (2021) On the drivers of the fertility rebound. Econ Chang Restruct 54:821-845

Munshi K, Myaux J (2006) Social norms and the fertility transition. J Dev Econ 80(1):1-38

Myrskylä M, Kohler H-P, Billari F (2009) Advances in development reverse fertility declines. Nature 460(7256):741-743

Nakagaki Y (2019) Convex relationship between fertility and gender gap. Econ Bull 39(3):2014-2026

Ohinata A, Varvarigos D (2019) Demographic transition and fertility rebound in economic development. Scandinavian J Econ 122:1640-1670

Omori T (2009) Effects of public education and social security on fertility. J Popul Econ 22:585-601

Oswald AJ (1997) Happiness and economic performance. Econ J 107(445):1815-1831

Palivos T (2001) Social norms, fertility and economic development. J Econ Dyn Control 25(12):19191934

Park S (2018) A structural explanation of recent changes in life-cycle labor supply and fertility behavior of married women in the United States. Eur Econ Rev 102:129-168

Pool VK, Stoffman N, Yonker SE (2015) The people in your neighborhood:Social interactions and mutual fund portfolios. J Financ 70(6):2679-2732

Siegel C (2017) Female relative wages, household specialization and fertility. Rev Econ Dyn 24:152-174

Strulik H (2004) Economic growth and stagnation with endogenous health and fertility. J Popul Econ 17(3):433-453

Willis RJ (1973) A new approach to the economic theory of fertility behavior. J Polit Econ 81(2):S14-S64

Young A (2011) The Gini coefficient for a mixture of Ln-Normal populations LSE Research Online Documents on Economics, vol 54246. London School of Economics and Political Science, LSE Library

Zeman K, Brzozowska Z, Sobotka T, Beaujouan E, Matysiak A (2017) Cohort Fertility and Education Database. Methods Protocol. Available at https://www.cfe-database.org (accessed on 3/10/2021)

Publisher's note Springer Nature remains neutral with regard to jurisdictional claims in published maps and institutional affiliations. 